\title{
Direct Ignition of a High Performance Hydrogen Peroxide Hybrid Rocket with 3-D Printed Fuel
}

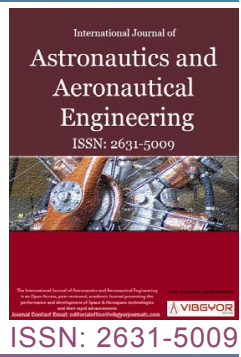

\section{Stephen A Whitmore*}

Mechanical and Aerospace Engineering Department, Utah State University, USA

\begin{abstract}
Development of a high-performing hybrid rocket system that employs $90 \%$ hydrogen peroxide and 3-D printable thermoplastic materials is reported. Traditionally, high-grade peroxide has been employed as a monopropellant using noble-metal catalysts to initiate thermal decomposition. Catbeds beds are expensive, heavy, and contribute no propulsive mass to the system. Catbeds exhibit limited operational lifetimes, and are often rendered inactive due to the high temperatures of thermal decomposition. The presented alternative thermallydecomposes the injected peroxide stream using an electrostatic ignition system, where as a moderate electric field is introduced to the additively layered ABS fuel grain. Electrostatic arcs are induced within the 3-D printed surface features, and produce sufficient pyrolyzed fuel vapor to induce spontaneous combustion when a flow of gaseous oxygen is introduced. Heat released is sufficient to thermally decompose the injected peroxide stream. The liberated heat and oxygen from decomposition drive full combustion along the length of the fuel grain. Gaseous oxygen pre-leads as small as $250 \mathrm{~ms}$ reliably initiate combustion. Multiple on-demand relights are provided with this system. Achieved laboratory specific impulse values exceed $215 \mathrm{~s}$ under ambient conditions, with a projected vacuum value exceeding $300 \mathrm{~s}$. Density specific impulse values exceeding $4000 \mathrm{~N}$-s/liter are achievable with this system.
\end{abstract}

\section{Keywords}

Hybrid rockets, Green propellants, Hydrogen peroxide, Additive manufacturing, Thermaldecomposition

\section{Nomenclature}

$A^{*}$ : Choking Area of Nozzle, $\mathrm{cm}^{2} ; \mathrm{c}^{*}$ : Characteristic Velocity of Propellants, $\mathrm{m} / \mathrm{s} ; \mathrm{f}$ : Peroxide Mass Concentration; $I_{s p}$ : Specific Impulse, $s ; \mathrm{M}_{\mathrm{H} 2 \mathrm{O}}$ : Water Mass, g; $\mathrm{M}_{\mathrm{H} 2 \mathrm{O} 2}$ : Peroxide Mass, $\mathrm{g} ; \mathrm{M}_{\mathrm{w}}$ : Molecular Weight, $\mathrm{kg} /$ $\mathrm{kg}-\mathrm{mol} ; \dot{m}_{\text {total }}$ : Total Massflow through Nozzle Exit, $\mathrm{g} / \mathrm{s} ; \mathrm{O} / \mathrm{F}$ : Oxidizer/Fuel Ratio; $\mathrm{P}_{\text {catbed }}$ : Catbed Exit Pres- sure, $p$ sia; $P_{\text {chamber }}:$ Pressure at Combustor Inlet, psia; $P_{0}$ : Chamber Stagnation Pressure, $p s i a ; P_{\text {chamber }}$ T e $\mathrm{m}$ perature at Combustor Inlet, psia; $T_{0}$ : Stagnation or Flame Temperature, $K$; $t$ : Time, $s ; \eta$ : Catalyst Decomposition Efficiency; $\gamma$ : Ratio of Specific Heats; $\rho_{\text {fuel }}$ : Solid Fuel Density, $\mathrm{g} / \mathrm{cm}^{3} ; \rho_{\mathrm{H}_{2} \mathrm{Ostd}}$ : Standard Density of Water, $1.0 \mathrm{~g} / \mathrm{cm}^{3} ; \rho_{o x}$ : Oxidizer Density, $\mathrm{g} / \mathrm{cm}^{3} ; \rho_{\text {Isp }}$ : Density Specific Impulse, $N$-s/liter.

\footnotetext{
*Corresponding author: Dr. Stephen A Whitmore, Professor, Utah State University Mechanical \& Aerospace Engineering Department, 4130 Old Main Hill/UMC 4130, Logan UT 84322-4130, USA

Accepted: January 03, 2019; Published: January 05, 2019

Copyright: (C) 2019 Whitmore SA. This is an open-access article distributed under the terms of the Creative Commons Attribution License, which permits unrestricted use, distribution, and reproduction in any medium, provided the original author and source are credited.

Whitmore. Int J Astronaut Aeronautical Eng 2019, 4:021
}

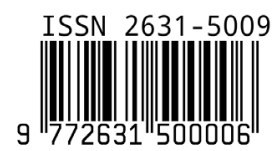




\section{Introduction}

Although the market for commercially designed and manufactured small spacecraft has grown enormously during the last decade, technology development has mostly centered on spacecraft bus design and miniaturization of sensor components. The space-launch industry has generally not kept pace with the growth trend. With the current stateof-the art, the only available for small commercial, commercial or academic payloads to reach orbit is by "rideshare".

A "rideshare" is defined as a secondary payload, smaller in size and weight than the primary payload, that is placed into orbit by a launch vehicle that is mostly paid for by the primary sponsor. Because the sponsor pays the lion's share of the launch costs, the secondary payload receives a substantially reduced launch price in exchange for trade-offs with regard to the payload's final orbit and launch schedule. These tradeoffs typically include having little or no control over the launch date and time, the final orbital parameters, or the ability to halt the launch and remove the payload should a payload failure occur during ground processing prior to launch.

Currently, these "rideshare" services are primarily provided by the DoD/NASA Evolved Expendable Launch Vehicle (EELV) using its secondary payload adapter (ESPA) ${ }^{\text {a }}$. SpaceX has also offered some secondary payload slots on its Falcon 9 launches; but these opportunities are limited $^{b}$. So unfortunately, with the current state of world launch capability, inadequate low earth orbit (LEO) "rideshare" launch opportunities are available to accommodate the demand for these NanoSat demonstration missions.

Furthermore, only a few specialized launch vehicles have upper stages with the ability for inspace restarts; these are typically reserved for expensive government-owned reconnaissance, communications, or command \& control satellites. For existing rideshare launch opportunities, nanoscale spacecraft are delivered to orbit as passive payloads and must accept whatever orbit they achieve during the deployment process. Secondary payloads, especially in the nanosat class, with little

aPerry B (2017) ESPA: An inexpensive ride to space for secondary payloads. MilsatMagazine.

${ }^{b}$ Foust J (2017) New opportunities for smallsatlaunches. The Space Review. or no ability determine their deployment orbit, will remain a novelty with little means to accomplish serious scientific, strategic, or commercial missions.

Finally, even when flown as secondary payloads, NanoSat launch costs are extremely high and are commercially prohibitive. Current launch costs are high for a variety of reasons, with human and environmental safety concerns being very high on this list. Clearly, a dedicated Nanosat launch vehicle is required to reduce costs and provide the required LEO access for NanoSats to achieve practical utility. This vehicle design must address the issues that make traditional launch costs so prohibitive.

The activity to be reported by this paper was initiated in response to this nano-launch challenge. Restartable, high performing launch vehicle stages in the $25-250 \mathrm{~kg}$ payload size class are not currently commercially available. The proposed hybrid "green-propellant" systems offer significant advantages over competing technologies in the areas of cost, safety, and mission capability. The resulting technology will fulfill the ever-growing mission demands of the extensive NanoSat market by enabling dedicated launch for CubeSat scale payloads.

\section{On the need for reduced hazard space- propulsion propellants}

Hydrazine $\left(\mathrm{N}_{2} \mathrm{H}_{4}\right)$ has been the standard for inspace propulsion for more than 50 years, and is by far the most commonly used monopropellant for primary spacecraft propulsion and attitude control thrusters. Hydrazine thrusters are simple, versatile, and dependable. Hydrazine is attractive as a spacecraft monopropellant because of its high hydrogen content. When passed through a catalyst the decomposition produces ammonia, nitrogen, and hydrogen gas [1]. The reaction is highly exothermic and associated gaseous products reach temperatures of exceeding $1300{ }^{\circ} \mathrm{C}$. Under realistic operating conditions hydrazine decomposition can produce specific impulse levels exceeding 220 seconds under vacuum conditions.

Unfortunately, hydrazine is a powerful reducing agent that poses serious biological and environmental concerns [2]. Hydrazine is extremely destructive to living tissues, and is a known human carcinogen. The US Environmental Protection Agency (EPA) classifies hydrazine as "highly toxic". Hydrazine possesses a high vapor pressure 
and boils readily at room temperature. Thus, there exists significant risk of respiratory contamination and special servicing procedures that employ full-pressure self-contained atmospheric protective ensemble (SCAPE) suits are required.

Although procedures are in place to allow hydrazine to be managed safely on tightly controlled military reservations and at government-operated launch facilities; the toxicity and explosion potential of hydrazine requires extreme handling precautions that increase operational complexity. Increasingly, with a growing regulatory burden, infrastructure requirements associated with hydrazine transport, storage, servicing, and clean-up of accidental releases are becoming cost prohibitive $[3,4]$.

A recent study $[5,6]$ by the European Space Agency Space Research and Technology Center (ESTEC) has identified two essential design elements to achieving low cost commercial space access and operations; 1) Reduced production, operational, and transport costs due to lower propellant toxicity and explosion hazards, and 2) Reduced costs due to an overall reduction in subsystems complexity and overall systems interface complexity. The ESA/ ESTEC study showed the potential for considerable operational cost savings by simplifying propellant ground handling procedures. Developing a nontoxic, stable "green" alternative for the most commonly used in-space propellant - hydrazine was highly recommended by the ESTEC study.

\section{Emerging alternatives to hydrazine-based propellants}

In response to this recommendation, for the past decade the US Air Force (USAF) and the Swedish Space Corporation (SSC) subsidiary ECological Advanced Propulsion Systems (ECAPS) have been pursuing less hazardous alternatives to hydrazine. The two most highly-developed "green-propellant" alternatives are based on aqueous solutions of the ionic liquids (Ils) Ammonium Dinitramide (ADN) [7], and Hydroxylamine Nitrate (HAN) [8].

However, both of the above-mentioned ILpropellants are toxic to organic tissue, and special handling precautions are required. IL-based propellants are not truly "green". Thus, the USAF has recently begun to refer to such IL-formulations more properly as having "reduced toxicity" properties.

Ionic liquids are water-soluble ammonium-salts that normally exist in solid form at room temperature, but melt below the boiling point of water. When dissolved in water these materials exhibit very strong ion-to-ion interactions. The surface charge attractions of these ions act to tightly hold them together in solution, and as a result produce a significantly lowered vapor pressure [9]. This lowered vapor pressure reduces the risk of toxicity posed by any escaped vapor from the monopropellant containment vessel. Spacecraft may be serviced without the use of SCAPE suits [10].

In August 2011, ECAPS announced the results of a year-long series of in-space tests of a 1-N thruster comparing their High Performance Green Propellant (HPGP) Brand Name LMP-103S, to hydrazine on the Prisma spacecraft platform. ECAPS claims that HPGP delivered equivalent-to-superior performance when compared to mono-propellant hydrazine [11]. NASA has recently selected the USAF-developed HAN-based propellant AF-M315E for its "Green Propellant Infusion Mission (GPIM)" [12].

Unfortunately, in additional to potential toxicity, there exist several key developmental issues associated with IL-based propellants that make them unsuitable for small spacecraft applications. The high water content makes IL-propellants notoriously hard to ignite. Multiple catalyst systems have been developed to augment IL ignitability; however, room temperature ignition does not currently exist. Catalyst beds must be preheated from $350-400{ }^{\circ} \mathrm{C}$ before and during ignition, and this preheat can consume up to 15,000 joules of energy. Catalyst beds and associated heating systems add significantly to the inert mass of the spacecraft and the highwattage preheat requirement presents a significant disadvantage for small spacecraft where power budgets are extremely limited. Finally, due to very slow reaction kinetics [13] at moderate pressures (2000-3000 kPa) system latencies associated with IL-based propellants are significant for moderate chamber pressures and may limit the usefulness of IL-propellants for reaction control systems.

Clearly, significant technology improvements must occur before IL-based systems can be employed as a primary propulsion unit or as part of the reaction control system for small spacecraft. With the current state of propulsion technology, the only proven non-hazardous propulsion alternative to hydrazine, and available for small 
ride-share payloads, is based on low-performing cold-gas thrusters.

\section{Hybrid rockets as a green propulsion alternative}

The inherent safety and environmental friendliness of hybrid rocket systems have been known for several decades. [14] Hybrids have the potential to act as an ideal "green" alternative to hydrazine. Historically, due to the lack of a reliable non-pyrotechnic, multiple-use ignition method, hybrid rockets have never been seriously considered as feasible for in-space propulsion. However, as will described later in Section III of this paper, this issue has been overcome by leveraging the unique electrical breakdown properties of certain 3-D printed thermoplastics [15]. The associated arc-ignition concept has been developed into a power-efficient ignition system that can be started, stopped, and restarted with a high degree of reliability. Details of this system will be presented in Section III of this report.

Hybrid rockets offer particular utility for the upper stages of a nano-launch vehicle. Although a hybrid rocket will increase the overall system dry mass compared to a solid-propellant motor, the capabilities to throttle, shut-down on demand, coast, and relight the motor, will the offset any lost in performance of the stage. Such a "smart-stage" would not only provide $\Delta V$ to enable the payload to reach orbit; but can also serve as an on orbit maneuvering system that allows precise placement of the payload.

Finally, orbital debris due to abandoned spacecraft is becoming a huge issue. It likely that United Nations regulations will soon demand active endof-lifetime deorbit. The system to be investigated here may also provide on-orbit maintenance or end-of-lifetime de-orbit capability [16].

Previously, the authors of this report have experienced considerable success with small spacecraft systems using gaseous oxygen (GOX) and 3-D printed thermoplastics as the propellants $[17,18]$. However, GOX was rejected for this upperstage application due to its low density, required storage pressures, and significant potential for fire hazards when stored in significant quantities at high pressures.

Due to its high density, hydrogen peroxide $\left(\mathrm{H}_{2} \mathrm{O}_{2}\right)$ was considered to be very promising oxidizer for this application. In order to achieve comparable density to $\mathrm{H}_{2} \mathrm{O}_{2}, \mathrm{GOX}$ would need to be stored at pressures above 10,000 psi. During this investigation USU has built a prototype $1 / 4^{\text {th }}$ scale motor and with a novel non-catalytic ignition system in order to gain experience with using peroxide in hybrid rocket system designs. This paper reports on the development and testing of that prototype system. Primary emphases are placed on ensuring reliable ignition, characterizing performance and enhancing the system performance, and developing regression rate curves.

\section{Hydrogen Peroxide as a Rocket Propellant}

Hydrogen peroxide is a powerful oxidizer whose chemical behavior is dominated by the weak nature of the peroxide bond. In pure form $\mathrm{H}_{2} \mathrm{O}_{2}$ is highly unstable, and very dangerous to work with. Due to its relative instability in pure form, peroxide is typically used in aqueous solutions [19]. Typical mass concentrations include $3-10 \%$ for medical applications, and 30\%-50\% for industrial and agricultural applications. Hydrogen peroxide solutions with mass concentrations greater than 95\% -- often referred to as high test peroxide (HTP) -- have been used extensively for propulsion applications [20].

Hydrogen peroxide readily undergoes a decomposition reaction where both oxidation and reduction occur simultaneously. The stoichiometric decomposition reaction

$$
\mathrm{H}_{2} \mathrm{O}_{2} \rightarrow \mathrm{H}_{2} \mathrm{O}+\frac{1}{2} \mathrm{O}_{2}+\text { heat }
$$

Is very energetic, producing up to $98.1 \mathrm{~kJ}$ for every mole of peroxide that is decomposed $(2.89 \mathrm{MJ} / \mathrm{kg})$. Figure 1 shows the progress of the decomposition reaction for a 95\% HTP solution concentration. Both the $75 \mathrm{KJ} / \mathrm{mol}$ activation energy and $98.1 \mathrm{KJ} /$ $\mathrm{mol}$ decomposition energy are shown on this plot.

In typical rocket applications a catalyst bed is used to lower the activation energy for decomposition. A properly-designed catbed lowers the activation energy to the point where a moderate amount of heat can initiate decomposition.

As examples, noble metal catalysts like platinum or silver can lower the activation energy to less than $15 \mathrm{~kJ} / \mathrm{g}$-mol. Reliable, room temperature, catalytic decomposition typically requires very high concentrations of peroxide, often greater than $95 \%$ [21-23]. 


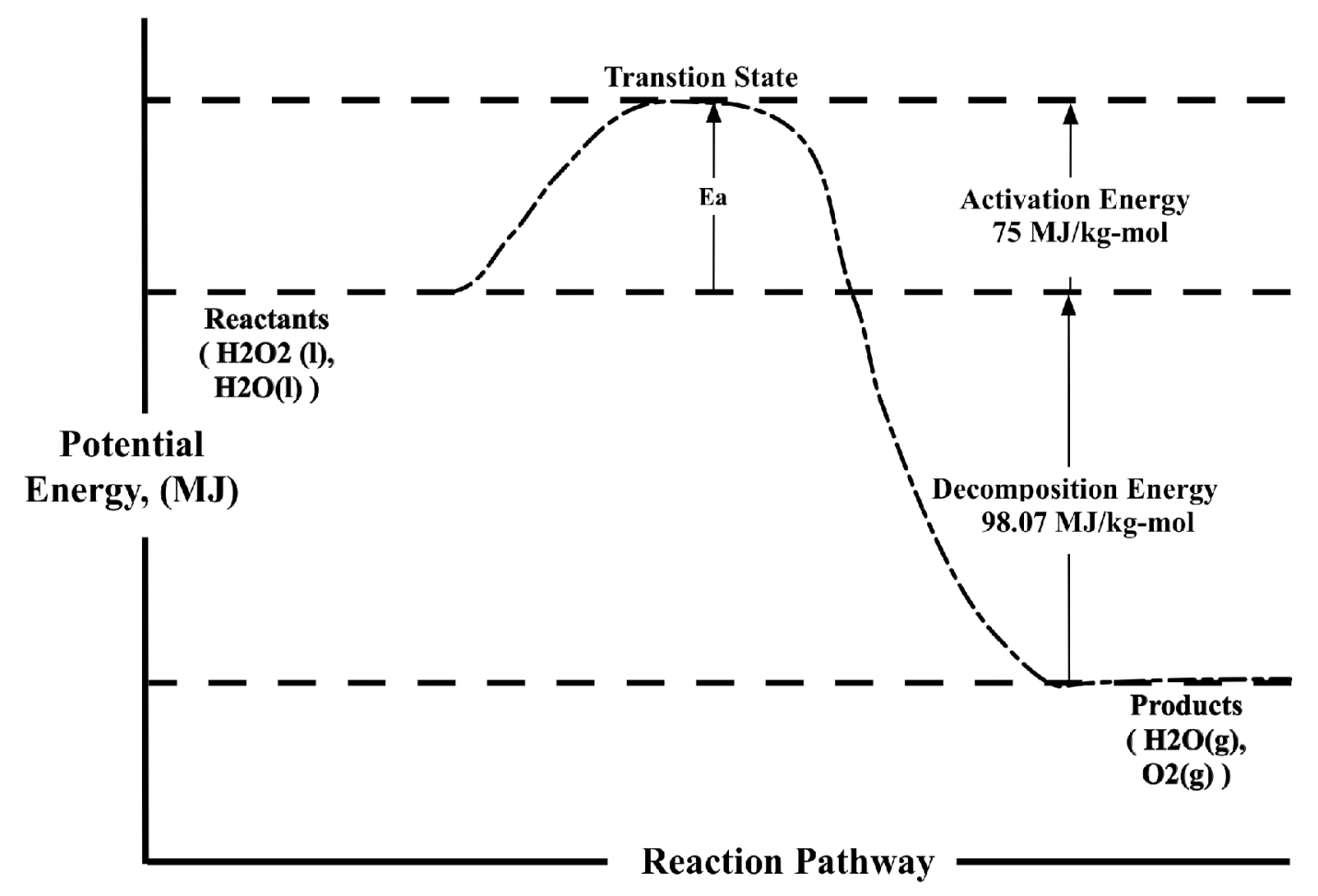

Figure 1: 95\% Peroxide decomposition energy state.

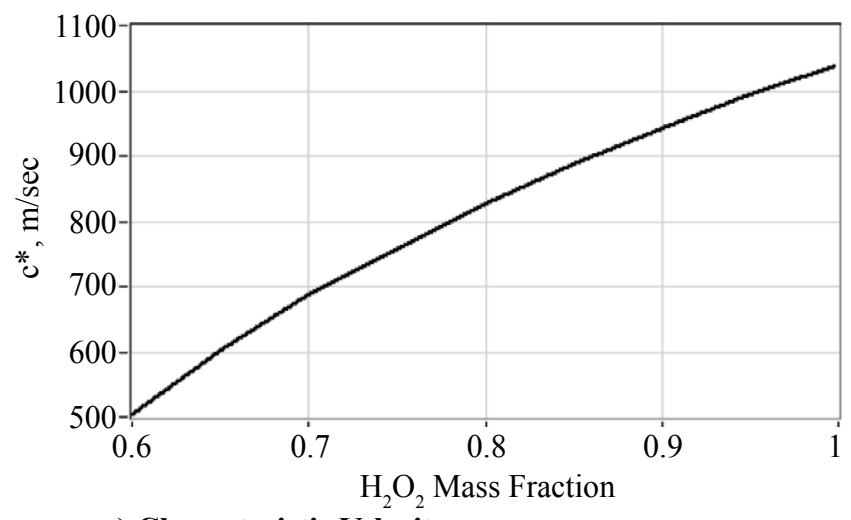

a) Characteristic Velocity

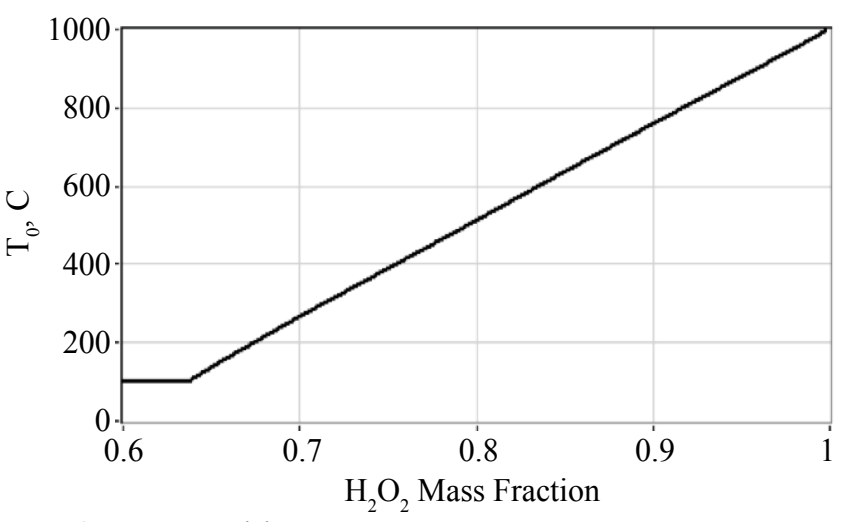

b) Decomposition Temperature

Figure 2: Monopropellant performance of $\mathrm{H}_{2} \mathrm{O}_{2}$ solutions as a function of mass concentration.

At high concentrations $\mathrm{H}_{2} \mathrm{O}_{2}$ is unstable and slowly decomposes with time. Because of this property, $\mathrm{H}_{2} \mathrm{O}_{2}$ is typically stored with a stabilizer in a weakly acidic solution. These stabilizing materials have the detrimental effect of gradually deteriorating any catalyst material in use. This poisoning will eventually render the catbed ineffective. The intense heat of decomposition can also render most catalyst materials ineffective after just a few uses. Because they are constructed from very expensive noble metals, the associated limited use lifetime makes catalyst beds quite expensive to build and maintain.
Additional drawbacks include a significant catbed weight that contributes nothing to propulsive mass of the system. Also, even at very high concentrations, a significant pre-heat of the catalyst bed is required prior to the initiation of the peroxide flow. Such a pre-heat may require energy and mass budgets that are not feasible for on-orbit operations. This combination of factors makes the use of catbeds energy and mass inefficient. Their required use drives operating costs up, potentially to the point of being cost prohibitive for small systems requiring multiple reliable restarts. 


\section{Monopropellant peroxide performance}

When used as a monopropellant, the performance of an aqueous $\mathrm{H}_{2} \mathrm{O}_{2}$ solution drops rapidly as the solutions mass concentration becomes increasingly more dilute. Figure $2 \mathrm{a}$ illustrates this monopropellant performance drop off where the characteristic velocity,

$$
c^{*}=\frac{P_{0} A^{*}}{\dot{m}_{\text {total }}}
$$

Is plotted as a function of the percentage $\mathrm{H}_{2} \mathrm{O}_{2}$

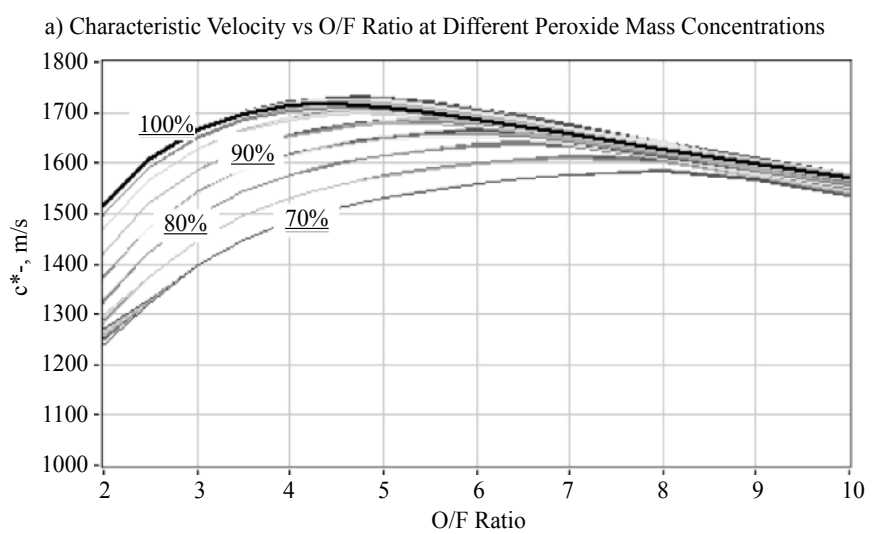

mass concentration. In Eq. (1) $c^{*}$ is the characteristic velocity, $P_{0}$ is the combustion chamber pressure at which decomposition occurs, $A^{*}$ is the equivalent choke-point cross sectional area, and $\dot{m}_{\text {total }}$ is the monopropellant massflow rate. Figure $2 \mathrm{~b}$ also plots the predicted decomposition temperature as a function of mass concentration. The presented data was calculated using the industry standard NASA chemical equilibrium code CEA [24]. The calculation assumes a $100 \%$ decomposition efficiency.

The monopropellant characteristic velocity

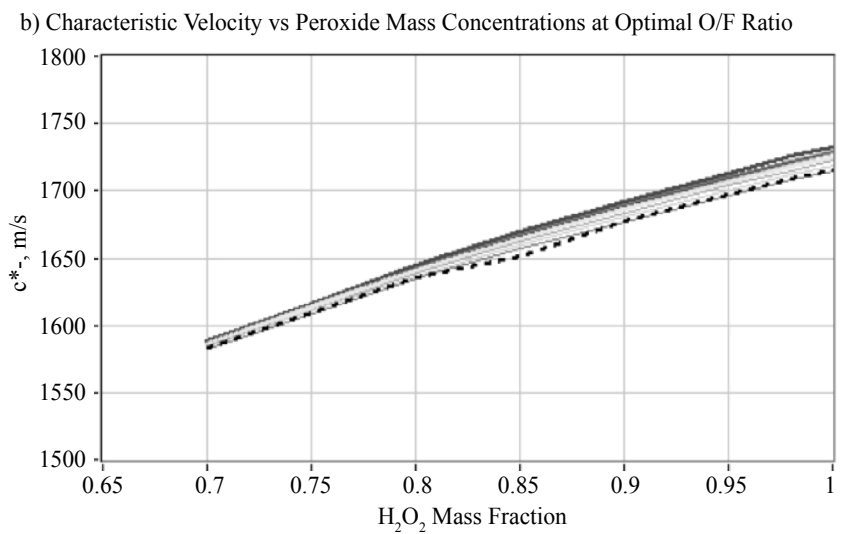

Figure 3: Hybrid performance of $\mathrm{H}_{2} \mathrm{O}_{2}$ as a function of solution mass concentration.

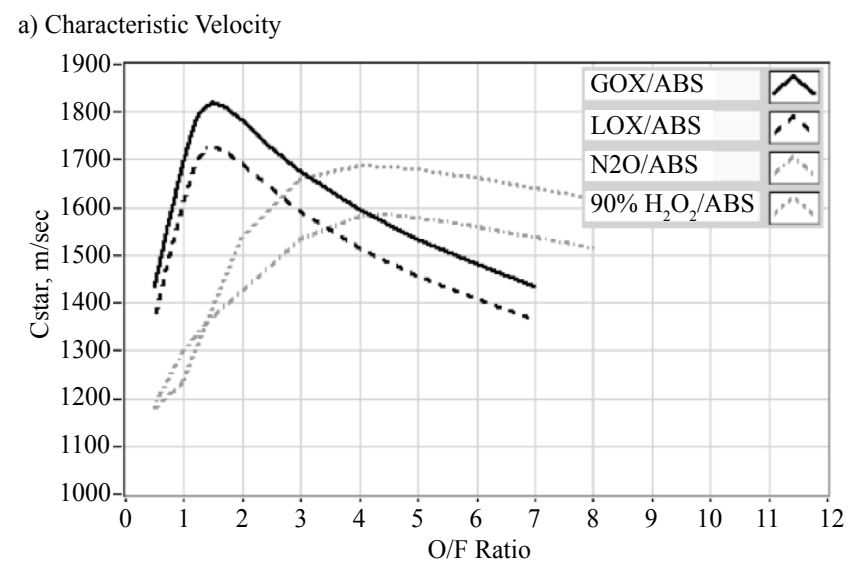

c) Vacuum Isp (25:1 Expansion Ratio)

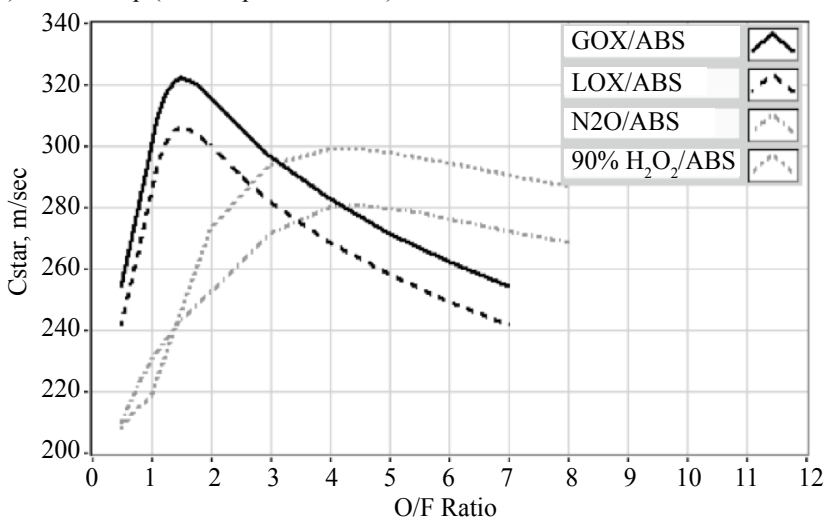

b) Effective Specific Gravity

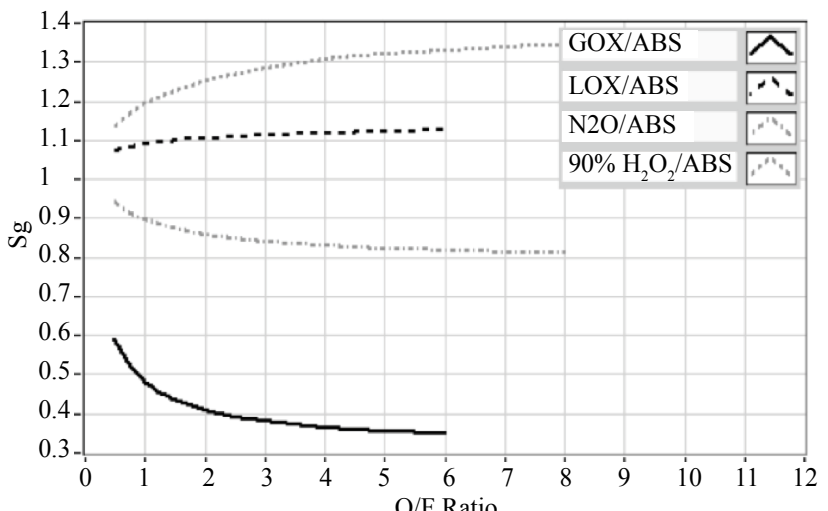

d) Vacuum Density Specific Impulse

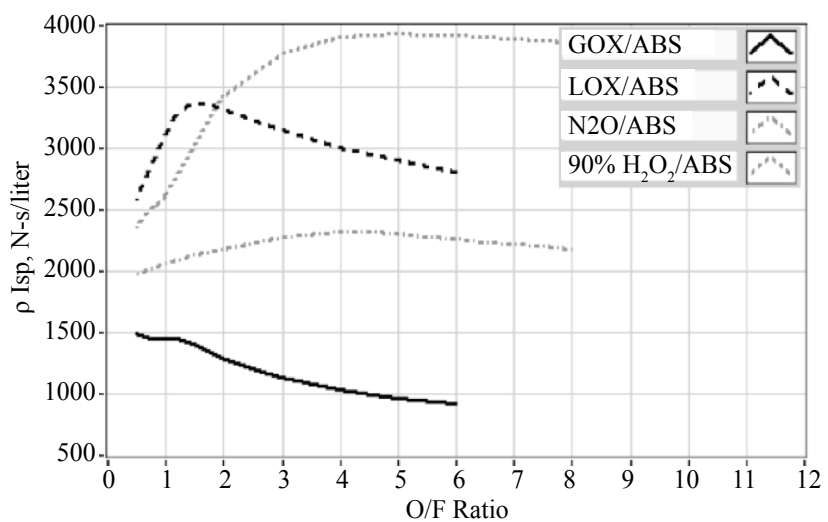

Figure 4: Performance comparisons of 4 commonly used hybrid oxidizers burned with ABS fuel. 
drops nearly linearly with mass concentration, and over the range from $80 \%$ to $100 \%, c^{*}$ drops by approximately $13.5 \mathrm{~m} / \mathrm{sec}$ for each \% of massdilution. At concentrations below $63.8 \%$ there is insufficient decomposition energy to boil away all of the water in the solution; thus, the temperature becomes fixed at $100^{\circ} \mathrm{C}$.

\section{Peroxide hybrid rocket performance}

When used as a hybrid bipropellant, in contrast to monopropellant applications, hydrogen peroxide does not exhibit this dramatic performance drop off with mass concentration. Figure 3 shows this property where peroxide is combined with a common 3-D printable thermoplastic, acrylonitrile butadiene styrene (ABS) as hybrid propellants. Figure 4 compares the performances of 4 different hybrid propellant combinations. These propellant combinations are GOX/ABS, liquid oxygen (LOX)/ ABS, nitrous oxide $\left(\mathrm{N}_{2} \mathrm{O}\right) / \mathrm{ABS}$, and $90 \% \mathrm{H}_{2} \mathrm{O}_{2} / A B S$.

Plotted on $3(\mathrm{a})$ is the characteristic velocity as a function of the $\mathrm{H}_{2} \mathrm{O}_{2}$ solution (oxidizer) to consumed $A B S$ (fuel) ratio $(O / F)$. These calculations were performed using the NASA CEA code (Ref. 9), assuming a range of combustion pressures of from $1000 \mathrm{kpa}$ (145 $p s i a)$ to $5000 \mathrm{kpa}$ (725 psia). This equilibrium calculation also assumes that sufficient energy is available to initiate the propellant combustion.

Note that at $90 \%$ concentration the hybrid characteristic velocity is only approximately $2 \%$ lower than occurs with a $100 \%$ solution concentration. For an $85 \%$ peroxide mass concentration the corresponding $c^{*}$ value drops by approximately $5 \%$. These hybrid propellant $c^{*}$ drops are contrasted with drops of $22 \%$ and $50 \%$ for $90 \%$ and $80 \%$ monopropellant peroxide.

Figure 4 demonstrates that peroxide, due to its high specific gravity, appears to be an ideal hybrid oxidizer for systems where volumetric efficiency is of primary importance, as in small spacecraft applications. Plotted on Figure 4 are (a) Characteristic velocity $c^{*}$, (b) Effective specific gravity $S_{g^{\prime}}$ (c) Vacuum specific impulse $I_{s p^{\prime}}$ and (d) Density specific impulse $\rho l_{s p}$. These calculations were performed assuming a combustion pressure of $1500 \mathrm{kpa}$ (217 psia). The vacuum specific impulse calculations assume a 25:1 nozzle expansion ratio.

At $90 \%$ mass concentration, the peroxide/ABS combination offers a significant improvement in volumetric efficiency compared to the other "green" hybrid oxidizers $\left\{G O X, L O X\right.$, and $\left.\mathrm{N}_{2} \mathrm{O}\right\}$ with a peak mass-density specific impulse $25 \%$ higher than $L O X / A B S$, and more than three times higher than $G O X / A B S$.

Two key insights can be gathered from the data presented by Figure 2, Figure 3 and Figure 4. First, hybrid $\mathrm{H}_{2} \mathrm{O}_{2} / A B S$ propellants have the potential to deliver significantly higher $c^{*}$ and a corresponding increase in specific impulse $\left(l_{s p}\right)$ than does monopropellant peroxide. Second, lowering the peroxide mass concentration for the hybrid does not hurt the equilibrium performance nearly as much as it does when peroxide is used as a monopropellant.

\section{Reduction of risk with $\mathbf{9 0 \%}$ peroxide}

The "forgiving" nature of peroxide concentration with regard to hybrid combustion performance is quite significant from an operational point of view. The high test peroxides (HTP) required for monopropellant applications, with concentrations greater than $95 \%$, are registered by the US Department of Transportation under the Code of Federal Regulations (CFR) as a Class 4 oxidizer, and as a DOT Class 4 unstable material [25]. As a class 4 oxidizer HTP can cause explosive reactions due to contamination or exposure to thermal or physical shock. Additionally, the oxidizer will enhance the burning rate and may cause spontaneous ignition of combustibles.

HTP is corrosive and "burns" skin and tissue upon contact. HTP can initiate decomposition of materials which in themselves are not likely to undergo explosive decomposition because they require a strong initiating source. HTP is an extremely dangerous material to work with. Storage of large quantities presents a significant explosion hazard. Regulations regarding the sale, use, transport, and storage of DOT Class 4 oxidizers are extremely stringent.

By contrast, at concentrations of $90 \%$ or lower, the propellant is reduced in hazard to a class 3 oxidizer. Regulations regarding the sale, use, transport, and storage of DOT Class 3 oxidizers are significantly less stringent than for DOT Class 4 oxidizers. These features offer the potential of developing a high performing system, but with a significantly lowered operating risk and a significantly a reduced regulatory burden. Thus, there exists a potential for significant costs savings. 


\section{Peroxide catbed design efficiency consider- ations for hybrid rockets}

The efficiency of the catbed has a significant effect on the decomposition temperature; thus, choosing an appropriate catbed geometry is critical in order to avoid a "wet start" that may affect ignitability of the system. The general non-efficient reaction for catalytic decomposition of peroxide is written as

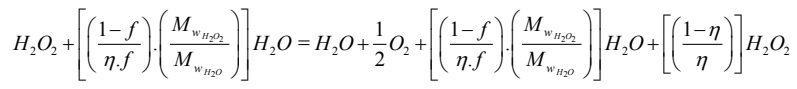

Where, $f$ is the peroxide mass fraction in the solution, $\eta$ is the decomposition efficiency, and the $M_{w}{ }^{\prime} s$ are the respective molecular weights of peroxide, $34.01 \mathrm{~kg} / \mathrm{kg}-\mathrm{mol}$, and water, $18.02 \mathrm{~kg} / \mathrm{kg}$ mol. Inspection of Eq. (2) shows that the "effective" solution mass ratio for inefficient decomposition is

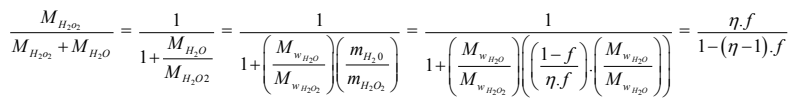

Using Eq. (3) and the data of Figure 2 and Figure 5 plots the predicted peroxide plume temperatures as a function of decomposition efficiency and peroxide concentration. For example, Figure 5 shows that a $90 \%$ peroxide solution with $\eta=100 \%$ decomposition efficiency results in a decomposition temperature of approximately $756{ }^{\circ} \mathrm{C}$. However, when the decomposition efficiency reduces to $90 \%$, the resulting decomposition temperature drops to only $370{ }^{\circ} \mathrm{C}$. When $90 \%$ peroxide is decomposed at $80 \%$ efficiency, the decomposition does not provide sufficient heating rate to vaporize all of the water in the solution, and the temperature rises to only $100{ }^{\circ} \mathrm{C}$. Even at $95 \%$ decomposition efficiency, the plume exiting the catbed barely exceeds $500{ }^{\circ} \mathrm{C}$ for a $90 \%$ peroxide solution.

\section{Effects of $\mathrm{H}_{2} \mathrm{O}_{2}$ plume expansion entering hybrid combustion chamber}

Assuming a typical in-line configuration where the catalyst bed lies upstream of the hybrid combustor; as the plume enters the cold combustion chamber, it instantaneously expands to ambient conditions. This expansion super cools the decomposition products, potentially dropping the temperatures to levels that are below the pyrolysis temperatures of the fuel. The data plotted on Figure 6 quantify this phenomenon. Here the decomposed peroxide plume temperature $\mathrm{T}_{0}$, entering the combustion chamber is taken from the data of Figure 5. Then assuming an adiabatic expansion from the catbed exit pressure $P_{\text {atbed }}$, to the local chamber pressure $P_{\text {chamber }}$, the pre-combustion chamber temperatures are calculated by assuming an adiabatic expansion,

$$
\frac{T_{\text {chamber }}}{T_{0}}=\left(\frac{P_{\text {chamber }}}{P_{\text {catbed }}}\right)^{\frac{\gamma-1}{\gamma}}
$$

Figure 6a plots the $\mathrm{H}_{2} \mathrm{O}_{2}$ plume pre-combustion temperature $T_{\text {chamber }}$ at various catbed to chamber pressure ratios $P_{\text {chamber }} / P_{\text {catbed }}$ for a $90 \%$ solution concentration. Curves for $\{100 \%, 98 \%, 95 \%, 93 \%$, $90 \%$, and $85 \%$ decomposition efficiencies are plotted. Also plotted are the pyrolysis temperatures for a typical ABS blend, [26] $\left(380^{\circ} \mathrm{C}\right)$ and the Arco R-45M [27] HTPB formulation. $\left(430{ }^{\circ} \mathrm{C}\right)$. Figure $6 \mathrm{~b}$ repeats the calculations for an $87.5 \%$ solution concentration.

Clearly, the peroxide injection temperatures drop very quickly as the plume expands into the combustion chamber. Once the pressure ratio drops below the choke point, approximately

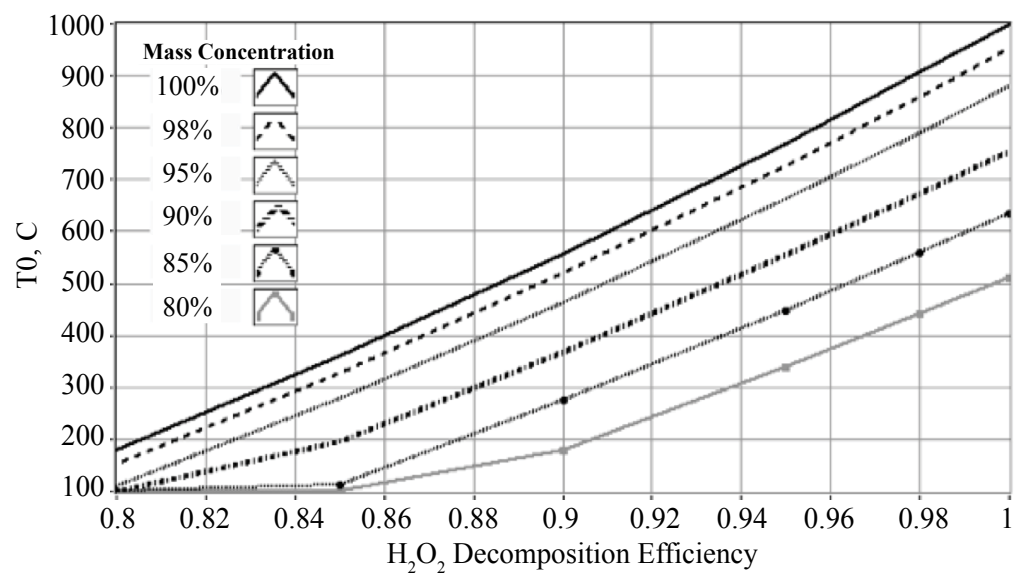

Figure 5: Estimated peroxide decomposition temperature as a function of catbed $\eta$ and $f$. 


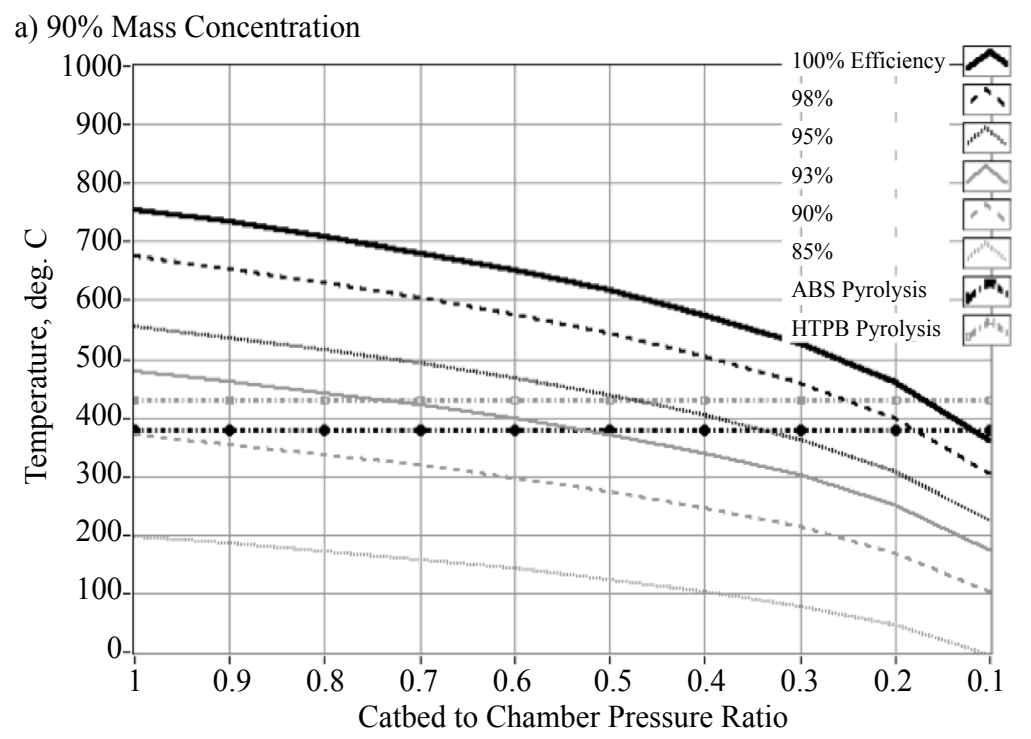

b) $87.5 \%$ Mass Concentration

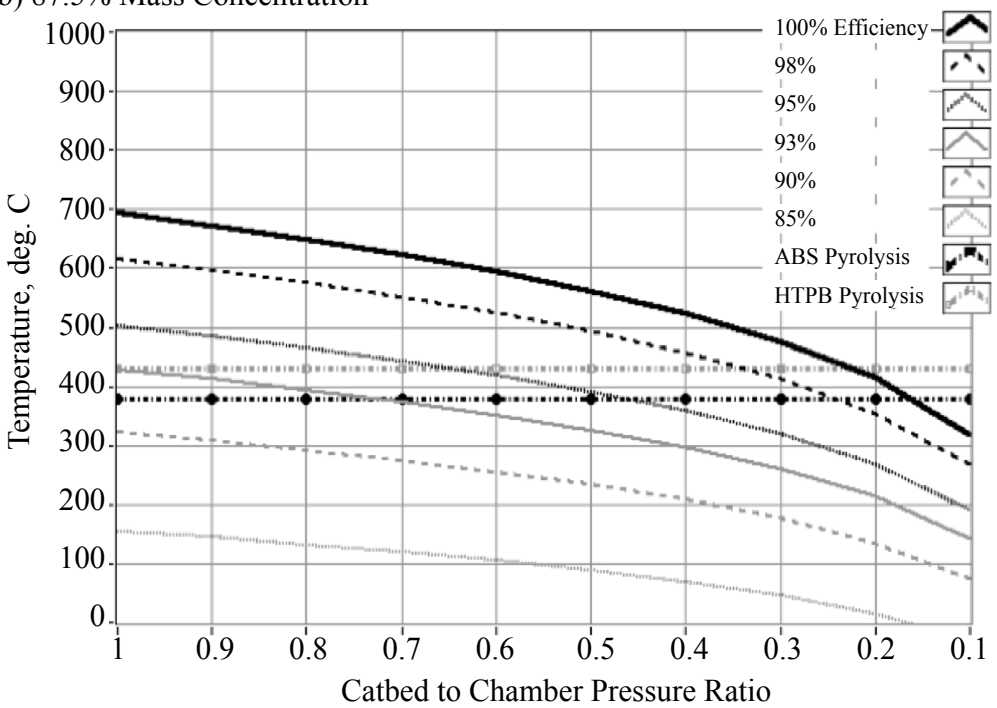

Figure 6: Peroxide plume temperature after expansion for multiple chamber pressure ratios.

$P_{\text {chamber }} / P_{\text {catbed }}<0.55$ for $90 \%$ peroxide, then a decomposition efficiency of near $93 \%$ is required to maintain the chamber temperature above the pyrolysis temperature of $A B S$. Once the plume temperature drops below this pyrolysis point, then hybrid ignition is nearly impossible.

For example, assuming a catbed exit pressure of $250 \mathrm{psia}$, then under steady flow conditions and perfect decomposition efficiency of a $90 \%$ solution, the fuel pyrolysis is not reached until the chamber pressure exceeds 30 psia. At $95 \%$ decomposition efficiency, a chamber pressure of 80 psia would be required to keep the entering plume temperature above the pyrolysis point. Without fuel pyrolysis, then full hybrid combustion cannot begin.

At even lower decomposition efficiencies, as often occur when the flow is first initiated into a cold motor, then the plume entering the combustion chamber cools sufficiently to allow the decomposed water vapor to re-condense into liquid form. Such a "soaked" fuel grain would be virtually impossible to ignite.

\section{Previous applications of hydrogen peroxide in hybrid rockets}

Recently, several groups and organizations including the Bloodhound SSC (OK) ${ }^{c}$ supersonic car team, ONERA (France) [28], and Nammo Raufoss (Norway), [29] and have tested $\mathrm{H}_{2} \mathrm{O}_{2}$ as an oxidizer in hybrid rocket systems. These projects

'Anon (2011) How to build a $1,000 \mathrm{mph}$ Car. The Economist. 
have all experienced varying degrees of success, while exhibiting some major technology gaps that still allow considerable room for improvement. Especially at larger scales, a difficulty with ignition and long ignition transients appear to be endemic to the application.

The UK Bloodhound team is developing a hybrid rocket motor using HTP (98\%) and the legacy solid rocket binder material, Hydroxyl Terminated Polybutadiene (HTPB), as propellants for its supersonic car design. This team has experienced considerably difficulty with getting their motor to light reliably and has resorted to "doping" the fuel grain with ammonium perchlorate (AP) in order to achieve and sustain ignition. This oxidizer addition to the fuel material has resulted in motor stability problems as well as difficulties extinguishing the motor after ignition.

The ONERA motor design relies on both pyrotechnic ignition and catalytic decomposition with swirl injection for ignition. The pyrotechnic ignition was able to successfully ignite the system using lower grade (87.5\%) peroxide. However, the catalytic system, based on a silver-screen catbed, required the use of $98 \%$ HTP. For both ONERA configurations, static test firings demonstrated considerable difficulty with initiating combustion when using a solid cone nozzle that produced a central flow distribution with very coarse fluid droplets. Instead the ONERA investigators found that combustion efficiency was considerably enhanced using a hollow cone injector nozzle. The hollow cone pattern produced the finest level of atomization with no central flow distribution. Ignition latencies as long as 2 seconds were observed for the catalytic ignition system. The pyrotechnic ignition system reduced the latencies, but was "single-shot" and did not allow for reignition of the motor.

The ESA-funded Nammo Raufoss (Project) has been ongoing since 2003, and is currently the most accomplished of the existing peroxide-hybrid programs. The Nammo design used HTPB as the accompanying. For this design the peroxide solution was decomposed using SAAB's proprietary catalyst bed design, with the resulting hot gasses injected into the combustion chamber through a vortex injector. The catalyst bed hybrid was able to work with peroxide concentrations as low as $87.5 \%$, but the catbed was quite large and made up a considerable fraction of the overall inert motor weight.

For the typical Nammo motor ignition sequence, after peroxide flow is initiated the chamber pressure gradual builds up from ambient to a plateau at approximately $1500 \mathrm{kPa}(220 \mathrm{psia})$. This "smoldering" buildup of chamber pressure takes slightly more than 2 seconds, followed a sharp rise in chamber pressure to approximately $2500 \mathrm{kPa}$ bars (360 psia). NAMMO refers to the initial pressure buildup as the "mono-propellant combustion mode". and the sharp rise and subsequent plateau as "hybrid combustion mode".

The previously-described expansion and adiabatic cooling phenomena are very likely the reasons for the large ignition latencies and the selfdescribed "monopropellant" combustion modes experienced by the NAMMO hybrid motors [14]. At $100 \%$ efficiency the decomposition temperature is only $695{ }^{\circ} \mathrm{C}$. Taking temperature data from Figure $6 \mathrm{~b}$ for $87.5 \%$ peroxide corrected for adiabatic expansion, in order to exceed pyrolysis temperature of their HTPB fuel $\left(430{ }^{\circ} \mathrm{C}\right)$ at $95 \%$ decomposition efficiency, the chamber-to-catbed pressure ratio needs to at least 0.6 . This results is precisely the pressure ratio $(1500 \mathrm{kPa} / 2500 \mathrm{kPa})$ at threshold where the Nammo motor transitions from "monopropellant" to "hybrid" combustion mode.

Development of a Low-Energy, Non-Pyrotechnic, Thermal Ignition System for $\mathrm{H}_{2} \mathrm{O}_{2} /$ ABS Hybrid Rockets

Based on the discussion of the previous section, the authors have concluded that unless very high concentrations of peroxide are used, catalytic methods for peroxide hybrid motors will always result in less than satisfactory ignition properties, with substantial ignition latencies. Legacy piled screen-mesh noble-metal catbed designs [30] developed for very high peroxide mass concentrations $(98 \%)$, are generally ineffective for mass concentrations of $90 \%$ or lower. Without an excessive length dimension, the piled screen-mesh design is simply not sufficiently active to allow the decomposition temperatures necessary for igniting the hybrid motor.

\section{Thermal decomposition ignition methods}

Instead, this project has emphasized the development of an alternative non-catalytic 
ignition method to initiate combustion. The alternative method is based on controlled thermal decomposition. In thermal decomposition sufficient heat to overcome the activation energy, depicted by Figure 1, is provided by an external source. The decomposed peroxide releases a large amount of energy that subsequently pyrolyzes the hybrid fuel. Decomposition also liberates a significant volume of gaseous oxygen that in turn burns with the pyrolized fuel.

Thermal decomposition of $\mathrm{H}_{2} \mathrm{O}_{2}$ is a complex process, and involves many intermediate steps including radical species. Although several authors have attempted to model this process with varying degrees of success [31-33], there is no generally accepted time-accurate model for the solutions with varying mass concentrations. Prior to the results to be reported in this study, restartable thermal decomposition methods for HTP hybrids have never been fully-successful.

Previous thermal decomposition methods have involved pyrotechnics where a large enthalpy rate is input in order to overcome the activation energy barrier. This approach presents a significant risk of an uncontrolled reaction. An uncontrolled reaction produces a large quantity of heat and the associated large volumes by-product gases. This sequence of events presents a significant explosion potential. Only, if the rate of thermal decomposition can be precisely controlled, will thermal decomposition produce a viable alternative to catalysis.

\section{Review of electrical arc-ignition technology}

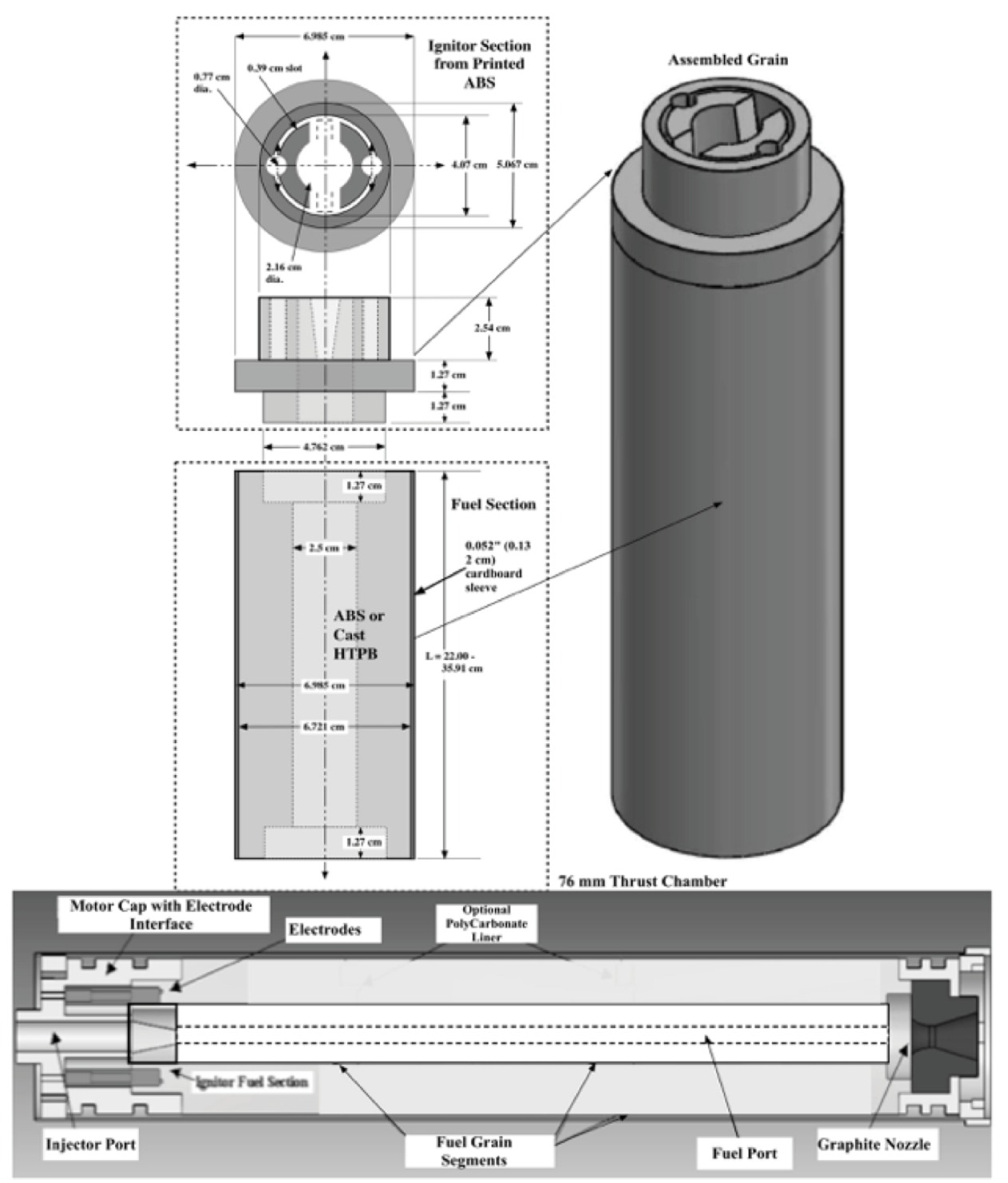

Figure 7: Schematic of 3-D printed ignitor, extruded ABS lower grain segment, and thrust chamber. 
The alternative-ignition approach to be presented here leverages the patented arc-ignition system developed for hybrid rockets by Utah State University [34,35]. The arc-ignition technology derives from the electrical breakdown properties of certain 3-D printed thermoplastics like Acrylonitrile Butadiene Styrene (ABS), Low Density Polyethylene (LDPE) and High-Impact-Polystyrene (HIPS). These properties were discovered serendipitously while investigating the thermodynamic performance of ABS as a hybrid rocket fuel [36].

Figure 7 shows an additively manufactured example of an ABS fuel grain with built in ignitor geometry. Pictured are the pre-combustion chamber that features two impingement shelves intended to trap and mix the injected oxidizer with the pyrolyzed fuel. Two electrodes, insulated by industry standard ESC connectors ${ }^{d}$, are embedded into the top face of the fuel grain. Dual redundant, solid-core copper wires are routed from the electrodes to small gaps located on the impingement shelves. The wires are insulated and protected from flame by 3-D printed circular "slots" that insert into the electrode wire gaps. The conducting paths terminate facing each other, flush with the combustion port surface, and exposed to the interior of the combustion chamber.

When an electrostatic potential is placed across the electrodes, charges flow from the energized electrode causing a localized electrostatic breakdown of the fuel material. This breakdown allows the charges to carve a path through the material. The resulting arc-track completes the circuit path to return electrode [37]. Current flowing through the material causes Joule heating and pyrolyzes some of the material hydrocarbons. Ignition of the pyrolized fuel vapors occurs as soon as oxidizer flow is initiated.

This arc-ignition concept has been engineered into a power-efficient system that can be started, stopped, and restarted with a high degree of reliability. On demand ignition has been demonstrated using compressed air, nitrous oxide $\left(\mathrm{N}_{2} \mathrm{O}\right)$ [34], gaseous oxygen [15], and hydrogen peroxide [38] as oxidizers. The arc ignition process is extremely energy efficient, requiring as little as 10 $W$ for less than one second. Typical ignition energies are less than 10 Joules. The arc-ignition system has been demonstrated across a wide range ambient

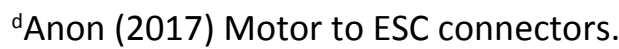

pressures including vacuum conditions [17].

Recently, a small prototype system that burned ABS in enriched air $\left(40 \% \mathrm{O}_{2}\right)$, was spaceflight tested at $170 \mathrm{~km}$ altitude. The payload was launched aboard a terrier Malemute launch vehicle from the NASA Wallops Flight Facility. The system successfully performed multiple restarts under hard-vacuum spaceflight conditions ${ }^{\mathrm{e}}$.

\section{Thermal decomposition of $\mathrm{H}_{2} \mathrm{O}_{2}$ using arc- ignition system}

In this approach the peroxide flow is pre-lead by a small flow of gaseous oxygen injected into a combustion chamber lined with the 3-D printed $A B S$ fuel. The arc-ignition system weakly initiates combustion between the injected oxygen and the fuel source, and is followed by the peroxide flow. Previous studies have demonstrated that GOX/ABS combustion generates temperatures exceeding $2800{ }^{\circ} \mathrm{C}$, and specific enthalpies greater than $8.5 \mathrm{MJ} / \mathrm{kg}$. Thus, with the properly tuned GOX pre-lead massflow, there exists sufficient energy to decompose the incoming peroxide flow, while simultaneously initiating full-length hybrid combustion. Once peroxide decomposition begins, then the additional energy of decomposition contributes to the overall combustion process. After the GOX pre-lead is terminated, Combustion is sustained by the oxygen liberated by the thermal decomposition of the peroxide.

Fuel grain design: Previous arc-ignition test prototypes have manufactured the entire fuel grain using 3-D printing. However, due to the associated costs of 3-D printing and the large volume of material that would be required for this testing campaign, only a small ignitor cap section was 3-D printed for each grain. The printed cap was bonded to an extruded ABS rod, machined to fit the appropriate dimensions, to complete the fuel grain. With this change the majority of the fuel grain volume consisted of the significantly cheaper extruded material, as opposed to the 3-D printed material. This approach resulted in considerable cost savings with no reduction in performance. The small 3-D printed cap section provided more than sufficient fuel pyrolysis to seed the flow with hydrocarbon vapor and initiate combustion.

The thrust chamber was developed from a

eAnon (2018) Prototype today, NASA launches USU student-built experiment into space. 
$76 \mathrm{~mm}$ hobby-rocket motor case with a graphite nozzle and retainer system. These components were well characterized during a previous research campaign [39]. The ignitor grain segments were manufactured on a Stratasys Dimension ${ }^{\circledR}$ 1200es 3D FDM printer ${ }^{f}$ using their standard-grade ABS stock material. The electrodes were manually installed into the assembly and the fuel grains and sealed with the printed "slots" described earlier. The fuel grains were completed by bonding the 3-D printed caps into the lower extruded sections using commercial grade ABS pipe joint cement. The ignitor grain segments were printed fully dense to match the extruded ABS material density of approximately $0.970 \mathrm{~g} / \mathrm{cm}^{3}$. Each ignitor grain

${ }^{\mathrm{f} A n o n}$ (2013) Dimension 1200es, Durability meets affordability. segment weighed approximately 110 grams. The $A B S$ grains were machined down to fit the $76 \mathrm{~mm}$ chamber from a 3" diameter extruded rod. The bonded grains were press-fit inserted into the motor case with no insulating sleeve. The extruded $A B S$ grain segments weighed approximately 700 grams each. Each completed fuel grain weighed approximately 810 grams. Figure 7 also shows the fuel grain and thrust chamber design features.

\section{Test motor hardware permutations}

Table 1 summarizes the parameters of the tested motor geometry, including the various injector permutations. Several iterations on the injector cap design, and different injector configurations, were evaluated during this testing campaign. Five different permutations on the $\mathrm{H}_{2} \mathrm{O}_{2}$ injector were evaluated. In order of test evaluation these

Table 1: Summary of $76 \mathrm{~mm}$ test motor geometry parameters.

\begin{tabular}{|c|c|c|c|c|}
\hline Fuel Material & Outside Diameter & Port Diameter & Length & Weight \\
\hline \multirow[t]{2}{*}{ ABS Ignitor Cap } & $6.985 \mathrm{~cm}(\max )$ & $2.16 \mathrm{~cm}$ & $5.08 \mathrm{~cm}$ & 95.5 grams \\
\hline & $4.762 \mathrm{~cm}(\mathrm{~min})$ & & & \\
\hline Fuel Grain & $6.985 \mathrm{~cm}$ & $2.16 \mathrm{~cm}$ & $23 \mathrm{~cm}$ & 800 grams (ABS) \\
\hline \multirow[t]{2}{*}{ Nozzle } & Throat Diameter & Exit Diameter & Exit Angle, deg. & Expansion Ratio \\
\hline & $1.087 \mathrm{~cm}$ & 2.083 & $12 \mathrm{deg}$. & $3.7: 1$ \\
\hline GOX & Injector Diameter: & Feed Pressure & Full Tank Pressure & Full Tank Mass \\
\hline Single Port & $0.476 \mathrm{~cm}^{\ddagger \ddagger}$ & 350-500 psig & 2200 psig & 65 grams \\
\hline 4-Port & $4 \times 0.238 \mathrm{~cm}^{\S \S}$ & " & " & " \\
\hline $\mathrm{H}_{2} \mathrm{O}_{2}$ & Injector Diameter: & $\begin{array}{l}\text { Regulator Feed } \\
\text { Pressure Settings }\end{array}$ & $\begin{array}{l}\text { N2 Pressurant Tank } \\
\text { Pressure }\end{array}$ & Full Tank Mass \\
\hline 1) Single Port & $0.381 \mathrm{~cm}^{* * *}$ & 350 psig/250 psig & 800-1200 psig & 525 grams \\
\hline 2) 5-Port & $5 \times 0.170 \mathrm{~cm}^{t+t}$ & $"$ & " & " \\
\hline 3) Full-Cone & $\begin{array}{l}0.254 \mathrm{~cm}, 120 \text { deg spray } \\
\text { angle } \neq \neq \neq\end{array}$ & $"$ & " & " \\
\hline 4) Hollow-Cone & $\begin{array}{l}0.2286 \mathrm{~cm}, 120 \mathrm{deg} \\
\text { spray angle }\end{array}$ & " & " & " \\
\hline 5) Hollow-Cone & $\begin{array}{l}0.1524,90 \text { deg spray } \\
\text { angle }\end{array}$ & $"$ & " & " \\
\hline
\end{tabular}

${ }_{\ddagger}^{\ddagger}$ Custom built from 1/4" NPT Brass Plug (https://www.mcmaster.com/\#50785K221) with drilled $0.476 \mathrm{~cm}$ diameter center port.

${ }^{\S \S}$ Custom built from 1/4" NPT Brass Plug with $4 \times$ drilled center $0.23 \mathrm{~cm}$ diameter ports.

${ }^{* * *}$ Custom built from 1/4" NPT Brass Plug with drilled center $0.381 \mathrm{~cm}$ diameter center port.

${ }^{+++}$Custom built from 1/4" NPT Brass Plug with $5 \times$ drilled $0.170 \mathrm{~cm}$ diameter ports.

${ }^{\ddagger \neq \ddagger} 1 / 4$ NPT Brass full cone injector, 0.1" port, 50o spray angle, McMaster-Car Part No. 32885K101, https://www. mcmaster.com/\#32885K101

\$\$\$1/4 NPT Brass hollow cone injector, 0.09" port, 50o spray angle, McMaster-Car Part No. 32825K111, https:// www.mcmaster.com/3282k111

****1/4 NPT Brass hollow cone injector, 0.06" port, 00o spray angle, McMaster-Car Part No. 33685K412, https:// www.mcmaster.com/\#33685K412002E 


\section{components were}

a) Single port injector, custom built from 1/4" NPT brass plugs,

b) Five-port straight injector, custom built from 1/4" NPT brass plugs,

c) Single port full-cone injector,

d) Single, large-port hollow-cone, swirl injector,

e) Single, small-port hollow-cone, swirl injector,

Items c) - f) were Commercial, Off-the Shelf (COTS) Products. Two different GOX injectors configurations were also evaluated. In the initial design the GOX flow was injected asymmetrically through a single port injector. This asymmetrical configuration was found to lead to erosive burning of the fuel grain ignitor section. To correct this issue, the GOX injector was redesigned to use 4 ports, symmetrically arranged around the central peroxide injector outlet.

As a cost saving measure, the test article was mostly assembled from existing parts, and was not optimized for peroxide combustion. After the system was passivated, reassembled, and leak checked, a preliminary set of hot-flow tests were performed to establish the feasibility and assess the effectiveness of arc-ignition system. These initial arc-ignition tests were performed using the single port injector, which proved to be ineffective by allowing a large 2-3 second latency before full ignition was achieved. The single port injector was replaced by a 5-port injector with the same flow cross sectional area. Once again, this injector design was ineffective. Full ignition was finally achieved by replacing the 5-port injector with a full cone injector.

Following guidance offered by Anthione, et al. [28] the burn performance was substantially improved by replacing the full-cone peroxide injector by a hollow-cone injector swirl injector. The hollow cone injector performed well; however, the asymmetric GOX injection port lead to erosion and survivability issues with regard to the injector cap section of the fuel grain. Swapping to the 4-port symmetrical GOX injector depicted greatly reduced the injector cap section erosion and enhanced the overall burn survivability of the system. The hollow-cone main injector, and 4-port GOX injector configurations exhibited the best overall ignition

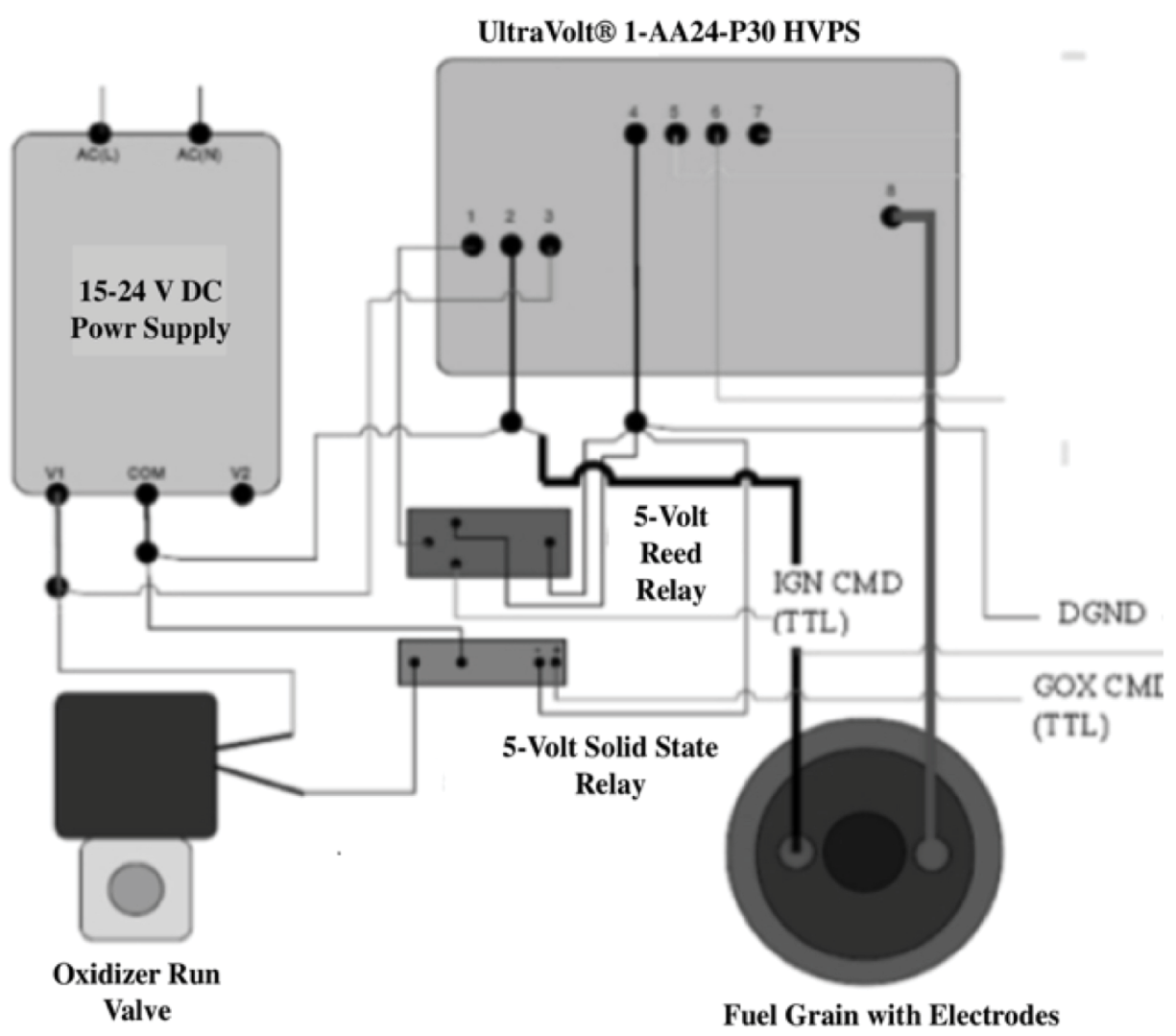

Figure 8: Ignition system electronic schematic. 
properties, and this configuration was taken forward to the performance characterization tests.

\section{Description of test apparatus and instrumen- tation}

This section describes the hardware designs and the associated permutations that were used during the development and characterization test phases of this project. As a cost-saving measure, much of the test hard ware used in this campaign was borrowed from previous test articles and adapted for this campaign. By no means are the presented configurations optimized for peroxide combustion.

\section{Ignition system electronics}

Figure 8 shows the layout of the arc-ignition system electronics, including the main valve actuation electronics. The ignition system power processing unit (PPU) is based on the UltraVolt ${ }^{\circledR}$ line of high-voltage power supplies (HVPS) ${ }^{g}$. This HVPS provides the inductive ignition spark that pyrolyzes sufficient ABS material to seed combustion. The 30watt C-series HVPS units take a 15-volt DC input to provide a high voltage output up to $1000 \mathrm{~V}$, with a $30 \mathrm{~mA}$ current-limit. The entire low-profile HVPS unit weighs approximately 142 grams, and has

${ }^{g}$ Anon (2018) DC-to-HVDC single-output high voltage cap-charging modules. UltraVolt Inc. dimensions $9.4 \times 3.8 \times 1.96 \mathrm{~cm}$.

\section{Test stand description}

A custom test-stand made from peroxidecompatible materials was built at USU to support peroxide testing activities. Figure 9 shows the Piping and Instrumentation Diagram (P\&ID) of the System. The instrumentation pallet sits on the lower shelf of the test cart. The system features a 1-liter capacity $\mathrm{H}_{2} \mathrm{O}_{2}$ run tank pressurized by nitrogen gas with the top-pressure set by a manually-adjustable regulator. A separate 1.5 liter, 2000 psig GOX tank supplies the ignitor flow. Two calibrated venturi flow meters allow direct measurements of both $\mathrm{H}_{2} \mathrm{O}_{2}$ and $\mathrm{GOX}$ massflow rates. The $\mathrm{H}_{2} \mathrm{O}_{2}$ injector inlet, GOX injector inlet, and the motor headend (chamber) pressures are also measured. The flow temperature at the $\mathrm{H}_{2} \mathrm{O}_{2}$ inlet The test sled load structure was fabricated using commercially available aluminum "t-slot". The data acquisition and control system was all contained within a single box mounted to the lower shelf of the test cart.

Two National Instruments data acquisition and control devices manage motor fire control, and test data logging. Communications to the test stand are managed by an operator-controlled laptop via universal serial bus (USB) using amplified extension

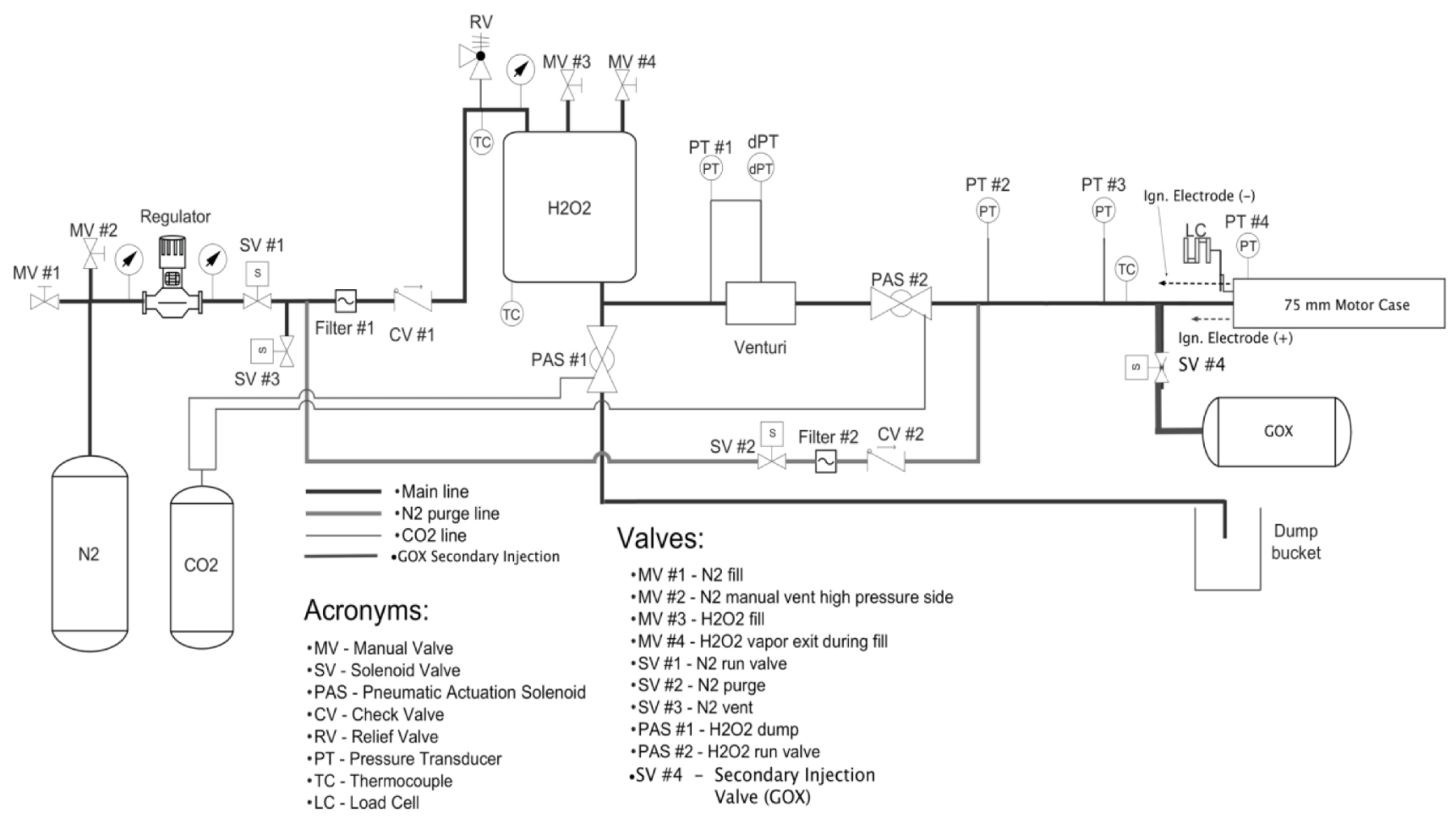

Figure 9: Piping and instrumentation diagram (P\&ID) of motor test systems. 
Table 2: Summary of the peroxide/ABS burn characterization tests.

\begin{tabular}{|c|c|c|c|c|c|c|c|c|c|c|c|}
\hline $\begin{array}{l}\text { Burn No. } \\
\text { (Grain } \\
\text { No.) }\end{array}$ & $\begin{array}{l}\text { Burn } \\
\text { Time, } s\end{array}$ & $\begin{array}{l}\% \mathrm{H}_{2} \mathrm{O}_{2} \\
\text { Conc. }\end{array}$ & $\begin{array}{l}\text { Inj. Pf, } \\
\text { psia }\end{array}$ & $\begin{array}{l}\text { Chamb. } \\
P_{c^{\prime}} \text { psia }\end{array}$ & $\begin{array}{l}\text { Thrust, } \\
N\end{array}$ & $\begin{array}{l}I_{s p}, s \text { peak } \\
\text { (cumulative) }\end{array}$ & $\begin{array}{l}\text { Port Dia., } \\
\text { cm start, } \\
\text { (end) }\end{array}$ & $\begin{array}{l}\text { Total } \\
\text { Mass } \\
\text { flow, } \\
\text { g/sec }\end{array}$ & $\begin{array}{l}M_{\text {fuel }} \\
\text { burned, } \\
\text { g }\end{array}$ & $\begin{array}{l}\text { Mean O/F } \\
\text { Ratio }\end{array}$ & $\begin{array}{l}\text { Ign. } \\
\text { Energy, } \\
J\end{array}$ \\
\hline $1(1)^{*}$ & 2.92 & 89.4 & 180 & 150 & 122 & 212 (198) & $2.45(3.11)$ & 57.7 & 56 & 2.038 & 14.3 \\
\hline $2(1)^{*}$ & 3.11 & 87.0 & 178 & 148 & 118 & 211 (196) & 3.11 (3.29) & 56.9 & 51 & 2.408 & 10.2 \\
\hline $3(1)^{*}$ & 2.93 & 92.4 & 175 & 142 & 114 & 209 (196) & $3.30(3.64)$ & 54.6 & 48 & 2.698 & 9.8 \\
\hline $4(1)^{*}$ & 3.14 & 90.2 & 177 & 148 & 121 & 210 (197) & 3.64 (3.95) & 60.4 & 88 & 3.397 & 7.8 \\
\hline $5(2)^{* *}$ & 3.87 & 90.6 & 185 & 152 & 129 & $219(201)$ & $2.45(2.67)$ & 59.6 & 47 & 2.880 & 13.2 \\
\hline $6(2)^{* *}$ & 7.82 & 92.4 & 200 & 167 & 138 & $220(201)$ & 2.67 (2.97) & 64.2 & 99 & 3.386 & 8.2 \\
\hline $7(2)^{* *}$ & 4.11 & 90.7 & 195 & 165 & 137 & $218(200)$ & 2.97 (3.17) & 63.4 & 57 & 3.628 & 6.0 \\
\hline $8(2)^{* *}$ & 3.95 & 88.7 & 183 & 154 & 125 & 215 (196) & $3.17(3.42)$ & 59.2 & 58 & 4.219 & 5.3 \\
\hline $9(3)^{* * *}$ & 5.88 & 89.68 & 200 & 152 & 123 & $213(201)$ & $4.05(4.83)$ & 56.5 & 87 & 4.307 & 12.9 \\
\hline $10(3)^{* * *}$ & 10.3 & 91.7 & 204 & 157 & 135 & 215 (201) & $4.09(5.08)$ & 61.0 & 154 & 4.180 & 5.9 \\
\hline $\begin{array}{l}\text { Mean } \\
\text { (Std } \\
\text { Dev.) }\end{array}$ & $\begin{array}{l}4.8 \\
(2.47)\end{array}$ & $\begin{array}{l}90.3 \\
(1.69)\end{array}$ & $\begin{array}{l}187.8 \\
(10.7)\end{array}$ & $\begin{array}{l}153.8 \\
(7.7)\end{array}$ & $\begin{array}{l}126.2 \\
(8.2)\end{array}$ & $214.2(3.9)$ & N/A & $\begin{array}{l}59.4 \\
(3.1)\end{array}$ & $\begin{array}{l}74.5 \\
(33.6)\end{array}$ & $\begin{array}{l}3.110 \\
(0.77)\end{array}$ & $9.3(3.2)$ \\
\hline
\end{tabular}

"Single Port, Asymmetrical GOX Injector, $0.2286 \mathrm{~cm}$ Hollow Cone $50^{\circ}$ Spray Angle Peroxide Injector.

${ }^{* *}$ Four-Port Symmetrical GOX Injector, $0.2286 \mathrm{~cm}$ Hollow Cone 50 Spray Angle Peroxide Injector.

${ }^{* * *}$ Four--Port Symmetrical GOX Injector, $0.1524 \mathrm{~cm}$ Hollow Cone $90^{\circ}$ Spray Angle Peroxide Injector.

cables. The high flow rate $\mathrm{H}_{2} \mathrm{O}_{2}$ run valve operated by a $\mathrm{CO}_{2}$ pressurant tank. The signal to the run valve $\mathrm{CO}_{2}$ actuator is driven by TTL logic from the controlling laptop. Peroxide and GOX flows are initiated by separate solenoid valves.

\section{Summary of peroxide burn characterization test results}

The primary objective of this testing campaign was to demonstrate that hybrid rockets using $90 \%$ or less peroxide concentration could be reliably ignited, controllably stopped, and re-ignited. A secondary objective was to characterize the system performance, and to compare those results against existing systems.

\section{$\mathrm{H}_{2} \mathrm{O}_{2} / A B S$ ARC-ignition hybrid performance assessment tests}

As described previously, the initial phase of the development campaign examined various hardware permutation in order to understand the configuration elements that were essential to establishing reliable and repeatable ignition sequences. These early development tests are described in detail by Whitmore, et al. [40] Once the feasibility of achieving reliable arcignition was established, the primary focus of the remaining program turned to characterizing the achievable performance of the propellants. For the performance characterization testing campaign each grain was burned multiple times, and the motor disassembled after each test to allow intermediate mass measurements as a check on the accuracy of the real-time measurements.

Table 2 summarizes the results of the ABS characterization tests. A series of 10 ABS-fuel burns using three different fuel grains (multiple burns each) were performed for this testing campaign. Because of the startup transients, where the peroxide enters the motor in still in liquid form; the performance runs were gradually extended from the initial $3 \mathrm{sec}-$ ond duration to a length greater than 10 seconds. The longer runs were performed in order to allow the effects of the startup transient to diminish.

The first 4-burn set on grain 1 used the asymmetric single-port GOX injector described earlier in this section. The second 4-burn set on grain 2 used the 4-port symmetric GOX injector. All of the first- 8 characterization burns used the $0.2286 \mathrm{~cm}, 50^{\circ}$ hollow cone peroxide injector. The final two long-duration burns on grain three also used the 4-port GOX injector. The last two burns in this series swapped the original hollow cone injector with a smaller $0.1524 \mathrm{~cm}, 90^{\circ}$ hollow cone peroxide injector in order to examine the effects of the reduced injector size on the motor stability. Due to the long burn times, grain 3 could only be 

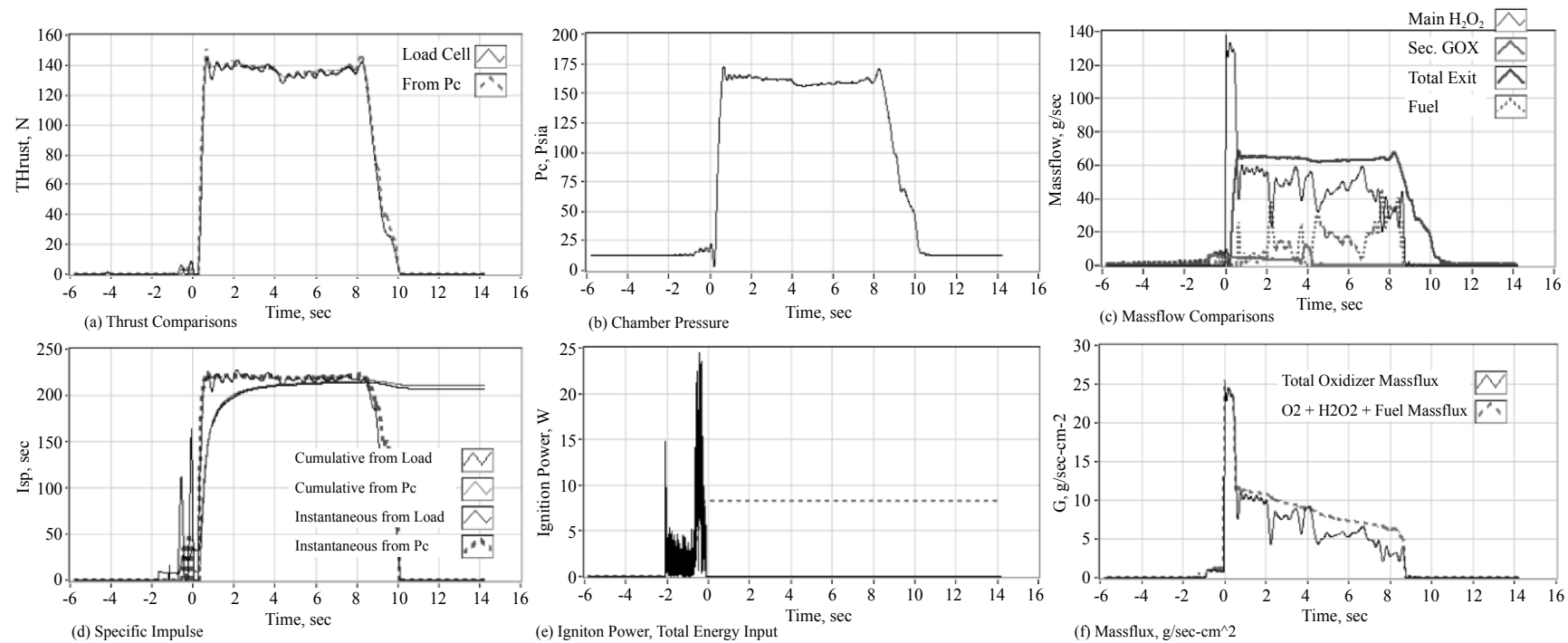

Figure 10: An 8-Second characterization burn using ABS fuel, and large-port hollow cone injector.
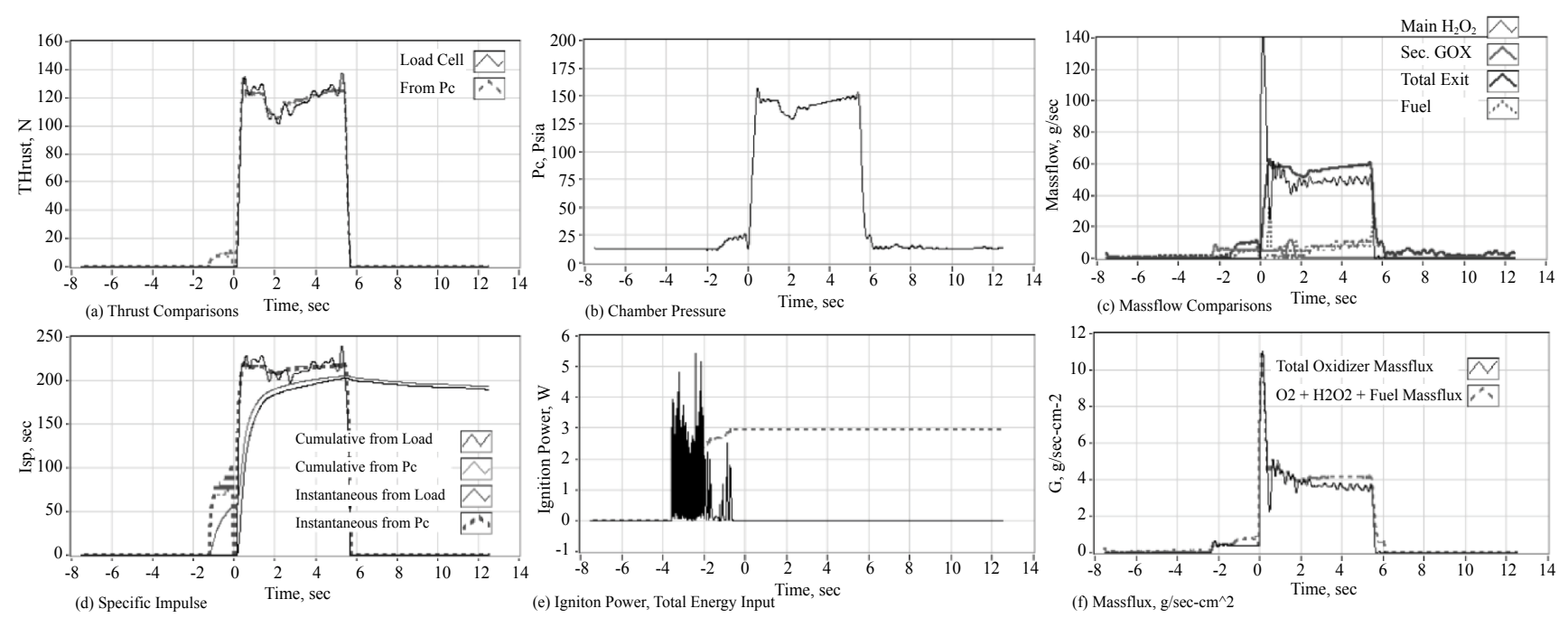

Figure 11: A 6-Second characterization burn using ABS fuel small-port hollow cone injector.

safely burned twice without risking motor case burn through.

For these performance characterization test the GOX flow time was shortened substantially with a pre-lead before the main valve opening of 1 second. The GOX valve remained open for 2 seconds after the main valve was opened. The peroxide valve was opened at time zero, and remained opened until all of the liquid in the peroxide run tank was exhausted. In order to achieve a wider variety of massflux rates during this burn series, the peroxide injector feed pressure of was varied by manually adjusting the regulator output over a range from 200 to 250 psig.

The resulting injector feed pressure varied over a range from 180 to 200 psia, with $p f$ for the first set of burns on grain 1 averaging approximately 180 psia, and approximately 190 psia for the set of burns on the grain 2 . The tabulated $\mathrm{O} / \mathrm{F}$ ratios were calculated by integrating the oxidizer massflow, and then dividing by the burned fuel mass.

\section{Example burn time histories}

Figure 10 and Figure 11 present representative time histories obtained for two longer-duration $\mathrm{H}_{2} \mathrm{O}_{2} / \mathrm{ABS}$ burn durations. Figure 10 plots the test results obtained using the larger-port hollowcone injector, and Figure 11 plots the test results obtained using the smaller-port hollow-cone injector. Plotted are (a) Directly measured (load cell) thrust and thrust calculated from chamber 
pressure using the De Laval flow equations, (b) Chamber pressure, (c) GOX, peroxide, nozzle exit, and fuel massflow rates, (d) Cumulative and instantaneous specific impulse values as calculated using both measured and calculated thrust levels, (e) Input power and energy levels, and (f) The oxidizer and total massflux through the fuel port.

The "steady" thrust, chamber pressure, specific impulse, and injector feed pressures values are calculated as the time-average of all values that are within $95 \%$ of the peak value. The cumulative specific impulse is calculated as a running summation of the total impulse and the total consumed propellant mass. This calculation includes the effect of the initial peroxide spike, and will necessarily produce a lower value.

Because of the startup transients, where unburned peroxide floods the combustion chamber during the startup transient, the integrated specific impulse values are consistently lower than the instantaneous values; however, and the burn time increases, the effects of the startup transient diminish and the integrated values begin to catch up with the instantaneous values. The mean and standard deviation values for each parameter are listed in the last row of this table.

Table 2 shows "instantaneous" mean $l_{s p}$ of approximately $212.6 \mathrm{~s}$, with a standard deviation of $+4.6 \mathrm{~s}$. The cumulative specific impulse is approximately $196.4 \mathrm{sec}$, with a standard deviation of $+3.29 \mathrm{~s}$. The instantaneous value for $I_{s p}$ is calculated by dividing the sensed thrust by the instantaneous nozzle massflow calculated from chamber pressure. The cumulative value for $I_{s p}$ is calculated by integrating the thrust and massflow over time, and dividing the accumulated total

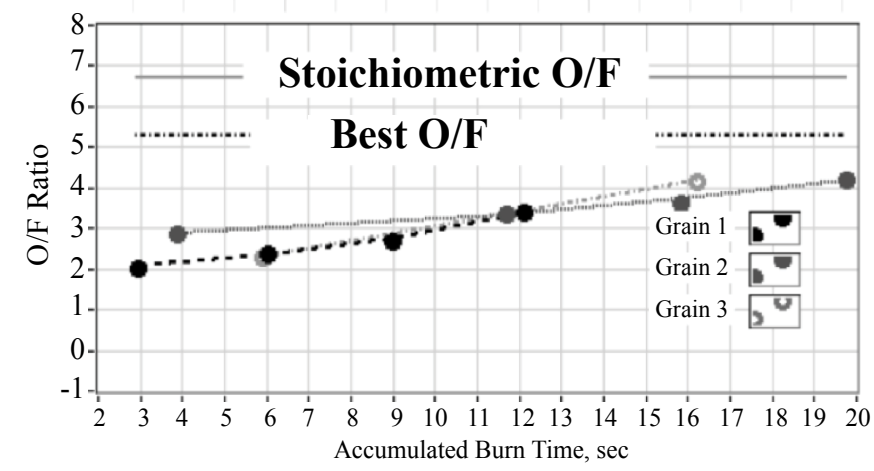

(a) Oxidizer-to-Fuel Ratio impulse by the total mass exited from the nozzle over time. The cumulative $l_{s p}$ includes the "lost mass" due to the initial transient unburned peroxide transient massflow.

Figure 12 plots the mean $O / F$ ratio (a) And the total ignition energy (b) As a function of the accumulated burn time for each fuel grain. Figure $12 a$ shows that the O/F ratios shifts towards a progressively leaner burn as the fuel port opens up and the mean massflux drops. Also noted is the ignition energy dropping with burn time. This observation supports the earlier discussion of current-path impedance dropping as the arc-path sets into the fuel grain. Agreements exhibited between each of the burned fuel grains of Figure 12 is excellent. All 3 fuel grains tended to burn slightly fuel rich, indicating that the motor length was slightly longer than optimal.

\section{Extrapolating the specific impulse values to hard-vacuum conditions}

The graphite nozzle used for this test series exhibited no measurable erosion during the entire characterization campaign. This low erosion rate is very likely due to the slightly fuel rich burns which left no remaining oxygen radicals to combine with the carbon throat.

At the chamber pressure levels required for stable motor operation, the nozzle configuration with and expansion ratio of 3.7:1 was slightly over-expanded at the test conditions. The result is a specific impulse approximately 5 seconds lower than would be achieved by the optimal configuration. However, since the nozzle configuration is well known and assuming that a higher expansion ratio has little effect upon the combustion chemistry; this effect can be accounted for, allowing the spe-

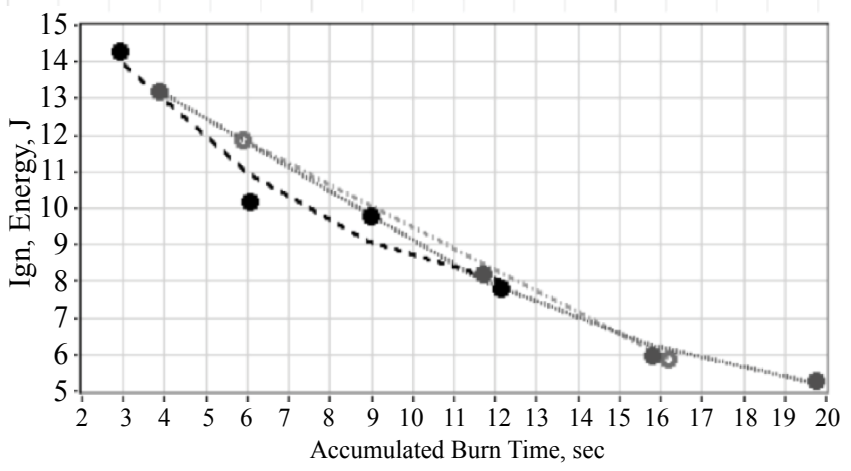

(b) Igniton Energy

Figure 12: Changes in peroxide/ABS O/F ratio and ignition energy as with accumulated fuel grain. 
Table 3: Extrapolating the test data to optimal and hard vacuum conditions.

\begin{tabular}{|c|c|c|c|c|c|c|c|c|}
\hline Condition & $\begin{array}{l}\text { Chamber } \\
\text { Pressure } \\
\mathrm{P}_{0}, \mathrm{kPa} \text { (psia) }\end{array}$ & $A^{*}, \mathrm{~cm}^{2}\left(\mathrm{in}^{2}\right)$ & $\begin{array}{l}p_{\infty}, k P a \\
\text { (psia) }\end{array}$ & $\begin{array}{l}V T_{o(K)} R_{g} \\
(J / k g-K)\end{array}$ & $A_{\text {exit }} / A^{*}$ & $p_{\text {exit }}, k P a$ (psia) & 1-D Thrust, N & $1-D I_{s p^{\prime}} s$ \\
\hline Actual Tes & 1060.I (153.76) & \multirow[t]{3}{*}{$\begin{array}{l}0.928 \\
(0.144)\end{array}$} & \multirow[t]{2}{*}{$\begin{array}{l}86.82 \\
(12.59)\end{array}$} & \multirow[t]{3}{*}{$\begin{array}{l}1.20 \\
2,720\end{array}$} & $3.7: 1$ & $52.0(7.54)$ & 125.2 & 213.6 \\
\hline Optimal Test & $1060 . I(153.76)$ & & & & 2.6:1 & $86.82(12.59)$ & 127.3 & 217.3 \\
\hline Vacuum & 1060.I (153.76) & & 0 & & $25: 1$ & $2.21(0.32)$ & 183.1 & 302.1 \\
\hline
\end{tabular}

Table 4: Comparison of propellant performance characteristics.

\begin{tabular}{|c|c|c|c|c|}
\hline Propellant & Hydrazine & LMP-103S & AF-M315E & $\mathrm{H}_{2} \mathrm{O}_{2} / \mathrm{ABS}$ Hybrid \\
\hline Flame Temperature & $600-750^{\circ} \mathrm{C}$ & $1600{ }^{\circ} \mathrm{C}$ & $1900^{\circ} \mathrm{C}$ & $2900^{\circ} \mathrm{C}^{\ddagger \ddagger \ddagger \ddagger}$ \\
\hline \multirow[t]{2}{*}{$I_{s p,} \sec$} & \multirow[t]{2}{*}{$220-225$} & 252 (theory), & 266 (Theory) & 324 (Theory) \\
\hline & & 235 (delivered) & 245 (Delivered) & 302 (Delivered) ${ }^{\S \S \S \S}$ \\
\hline Specific Gravity & 1.01 & 1.24 & 1.465 & $1.392\left(90 \% \mathrm{H}_{2} \mathrm{O}_{2}\right)$ \\
\hline \multirow{2}{*}{$\begin{array}{l}\text { Density Impulse, } \\
N \text {-sec/liter }\end{array}$} & \multirow[t]{2}{*}{22705} & 3125 (theory) & 3900 (Theory) & 4450 (Theory) \\
\hline & & 2915 (delivered) & 3650 (Delivered) & 4002 (Delivered) \\
\hline \multirow{2}{*}{$\begin{array}{l}\text { Preheat } \\
\text { Temperature }\end{array}$} & \multirow{2}{*}{$\begin{array}{l}315^{\circ} \mathrm{C} \text {, cold- } \\
\text { start capable }\end{array}$} & \multirow[t]{2}{*}{$300^{\circ} \mathrm{C}$} & \multirow[t]{2}{*}{$370^{\circ} \mathrm{C}$} & \\
\hline & & & & none-required \\
\hline $\begin{array}{l}\text { Required Ignition } \\
\text { Input Energy, Joules }\end{array}$ & N/A & $\begin{array}{l}18,000 \mathrm{~J} \text { (10 Watts } \\
@ 1800 \text { seconds) }\end{array}$ & $\begin{array}{l}27,000 \text { J (15 Watts @ } 1800 \\
\text { seconds }\end{array}$ & $\begin{array}{l}\text { 2-8 J (8-16 Watts for 250-500 } \\
\text { msec) }\end{array}$ \\
\hline $\begin{array}{l}\text { Propellant Freezing } \\
\text { Temperature }\end{array}$ & $1-2^{\circ} \mathrm{C}$ & $-7^{\circ} \mathrm{C}$ & $\begin{array}{l}<0{ }^{\circ} \mathrm{C} \text { (forms glass, no } \\
\text { freezing point) }\end{array}$ & $-10^{\circ} \mathrm{C}(90 \%$ concentration) \\
\hline Cost & $\$$ & $\$ \$ \$$ & \$\$\$ & $\$$ \\
\hline Availability & $\begin{array}{l}\text { Readily } \\
\text { Available }\end{array}$ & Restricted Access & Limited Access & Very Widely Available ${ }^{* * * *}$ \\
\hline $\begin{array}{l}\text { NFPA } 704 \text { Hazard } \\
\text { Class }\end{array}$ & & & & \\
\hline
\end{tabular}

${ }_{\ddagger \neq \neq \ddagger}$ Due to high pyrolysis energy of $A B S(3.1 \mathrm{MJ} / \mathrm{kg})$, the ABS Hybrid motors are self-ablative and do not get externally hot.

${ }^{\$ \$ \$}$ Extrapolated to vacuum conditions based on ground test data.

${ }^{* * * * *} 80-90 \%$ solutions easily condensable from $30 \%$ agricultural/food grade solutions.

${ }^{++++t}$ Ratings based on the highly-toxic constituent components, Hydroxyl Ammonium Nitrate (HAN) and 2-Hydroxyethylhydrazine (HEHN).

cific impulse values to be extrapolated to vacuum conditions using data from Table 2.

The extrapolation starts with the onedimensional de-Laval flow equations, fixes the throat geometry and chamber pressures at the values given by Table 1 and Table 2, and adjusts the nozzle exit area (and expansion ratio) to calculate the corresponding exit pressure, thrust, and specific impulse. Table 3 summarizes the results of these calculations. When the nozzle expansion ratio is lowered slightly to adjust the exit pressure upwards to match the ambient conditions, the mean peroxide/ABS specific impulse increases slightly to $217.3 \mathrm{~s}$, up approximately $1.7 \%$ from the mean measured value of Table 2 . Finally, when the nozzle exit is opened to a 25:1 expansion ratio, the $I_{s p}$ grows to greater than $300 \mathrm{~s}$, or about $30 \%$ higher than achieved under the actual test conditions.

\section{Discussion of Results}

Since a vacuum $I_{s p}$ of $200 \mathrm{~s}$ is approximately $30 \%$ higher than can be achieved by hydrazine, the current state of the art propellant for in-space propulsion; the result of the previous section is quite exciting. The issues associated with hydrazine were discussed in the introductory section of this paper. The peroxide/ABS propellants also 
significantly outperform the ionic-liquid "green" propellants, LMP-103S and AF-M315E; also offering a significantly lower required ignition energy input.

Table 4 compares the performance of the peroxide/ABS system to hydrazine, LMP-103S and AFM315-E [41]. The peroxide/ABS system outperforms the other propellants in every measureable category. When fully developed, a peroxide-based hybrid system could revolutionize the commercial space industry by offering a highperforming, but inherently safe, space propulsion option for rideshare payloads.

\section{Conclusion}

The Propulsion Research Laboratory at Utah State has recently initiated development of a novel laboratory hybrid thruster that employs medium grade hydrogen peroxide and additivelymanufactured $A B S$ as propellants. For this testing campaign, non-catalytic ignition method that thermally-decomposes the injected $\mathrm{H}_{2} \mathrm{O}_{2}$ stream is employed. This approach eliminates the need for expensive and mass inefficient catalytic systems. In this approach the peroxide flow is pre-lead by a small flow of gaseous oxygen injected into a combustion chamber lined with the 3-D printed ABS fuel. USU's patented arc-ignition system weakly initiates combustion between the injected oxygen and the fuel source, and is followed by the peroxide flow.

Released heat from burning fuel is sufficient to initial thermal decomposition of the injected peroxide stream. Heat liberated by thermal decomposition of the peroxide subsequently pyrolyzes sufficient fuel material to allow combustion with the oxygen liberated by the thermal decomposition of the peroxide. Full ignition latencies after initiation of the peroxide flow are typically less that 1 second. Multiple ondemand relights are provided with this system.

A variety geometries were investigated, and a best solution using a dual injection system with a symmetrical 4-port GOX injector and a single hollow cone peroxide injector. GOX pre-leads as short as 0.5 seconds were demonstrated to initiate combustion. At the low mass flux levels tested in this campaign, it was demonstrated that a pressure drop of at least 40 psia was required to ensure combustion stability.

Using the "best" available configuration as developed by the early tests, a series of evaluation burns were performed with data collected from 10 burns of 3 ABS fuel grains. The test results demonstrated a specific impulse value near 215 seconds.

The graphite nozzle used for this test series was slightly over-expanded for the chamber pressure level required for stable operation. Thus, the delivered $I_{s p}$ was approximately $2-3 \%$ lower than optimal for the test altitude. However, when the results obtained for the ambient test conditions are extrapolated to a hard-vacuum environment, by assuming a 25:1 expansion ratio nozzle, the specific impulse for both fuels grows to greater than $300 \mathrm{~s}$.

This result is very exciting, since a vacuum specific impulse of $300 \mathrm{~s}$ is approximately $30 \%$ higher than can be achieved by the current state of the art propellant for in-space propulsion, hydrazine; and greater than $25 \%$ higher than can be achieved by the two most promising emerging "green" inspace monopropellants, LMP-103s or AF-M315E. The peroxide/ABS system outperforms the other propellants in every measureable category. When fully developed, a peroxide-based hybrid system could revolutionize the commercial space industry by offering a high-performing, but inherently safe, space propulsion option for rideshare payloads, and other space propulsion applications. The technology is potentially market disruptive.

\section{Acknowledgements}

This work was funded through NASA STTR Solicitation T1.01, Affordable Nano/Micro Launch Propulsion Stages NASA STTR Phase II (T1.01-9931). The Award number is NNX16CD27C and is operated as a Collaborative Agreement (CA) between Utah State University, Logan UT and Parabilis Space Systems, Inc, San Marcos CA.

\section{References}

1. King SM, Marx PC, Taylor D (1969) The aerospace corporation shell 405 catalyst evaluation program, volume I: Physical and catalytic properties. Aerospace Report No. TR-066 (5210-10)-4, USAF Report No SAMO-TR-271, 1.

2. Choudhary G, Ilansen H, Donkin S, Kirman C (1997) Toxicological profile for hydrazines. US Department of Health and Human Services Public Health Service Agency for Toxic Substances and Disease Registry (ATSDR). Atlanta, GA: 1-224. 
3. De Sain, John D (2012) Green propulsion: Trends and perspectives.

4. Goldstein Edward (2012) The greening of satellite propulsion aerospace america. 50: 26-28.

5. Bombelli V (2003) Economic benefits for the use of non-toxic monopropellants for spacecraft applications. AIAA-2003-4783.

6. Haeseler D, Bombelli V, Vuillermoz P, Lo R, Marée $T$, et al. (2004) Green propellant propulsion concepts for space transportation and technology development needs. Proceedings of the 2nd International Conference on Green Propellants for Space Propulsion, Cagliari, Sardinia, Italy.

7. Venkatachalam S, Santhosh G, Ninan KN (2004) An overview on the synthetic routes and properties of ammonium dinitramide (adn) and other dinitramide salts. J Propellants Explosives Pyrotechnics 29: 178-187.

8. Rheingold AL, Cronin JT, Brill, TB, Ross FK (1987) Structure of Hydroxylammonium Nitrate (HAN) and the deuterium homolog. Acta Crystallographica 43: 402-404.

9. Hawkins TW, Brand AJ, McKay MB, Tinnirello $M$ (2010) Reduced toxicity, high performance monopropellant at the u.s. air force research laboratory. Making Safety Matter, Proceedings of the fourth IAASS Conference, Alabama, 680.

10. Meinhart D (1998) Selection of alternate fuels for HAN-BASED Monopropellants. 27th JANAFF PDCS and $16^{\text {th }}$ S\&EPS Joint Meeting, CPIA Pibl 674, 1: 143-147.

11. Persson M, Anflo K, Dinardi A (2012) A family of thrusters for ADN-based monopropellant LMP103S. $48^{\text {th }}$ AIAA/ASME/SAE/ASEE Joint Propulsion Conference \& Exhibit 30 July - 01 August 2012, Atlanta, Georgia.

12. Ronald A Spores, Aerojet (2013) Green propellant infusion mission propulsion system development. $49^{\text {th }}$ AIAA/ASME/SAE/ASEE Joint Propulsion Conference \& Exhibit, San Jose CA.

13. Katsumi T, Hori K (2010) Combustion wave structure of hydroxylammonium nitrate aqueous solutions. 46th AIAA/ASME/SAE/ASEE Joint Propulsion Conference \& Exhibit.

14. https://www.faa.gov/about/office_org/ headquarters_offices/ast/licenses_permits/media/ hazard.pdf

15. Stephen A Whitmore, Nathan R Inkley, Daniel $P$ Merkley, Michael I Judson (2015) Development of a power-efficient, restart-capable arc ignitor for hybrid rockets. Journal of Propulsion and Power 31: 1739-1749.

16. Whitmore SA, Chamberlain BL (2017) Consumable spacecraft structures with integrated, 3-D printed ABS thrusters. 53rd AIAA/SAE/ASEE Joint Propulsion Conference, AIAA Propulsion and Energy Forum.

17. Whitmore SA (2017) Three-dimensional printing of "Green" fuels for low-cost small spacecraft propulsion systems. Journal of Spacecraft and Rockets 55: 13-26.

18. Stephen A Whitmore (2017) Advantages of using additive manufacturing to build "Green" Fuels for hybrid propulsion. Int J Astronaut Aeronautical Eng 2.

19. Easton MF, Mitchell AG, Wynne-Jones WFK (1952) The behaviour of mixtures of hydrogen peroxide and water. Transactions of the Faraday Society 48.

20. Rusek JJ (1995) Hydrogen peroxide for rocket propulsion applications. Phillips Laboratory Report No. PL-TL-96-3015, Edwards AFB, California.

21. Munday TCF, Darbee LR, McCormick JC (1967) Investigation of decomposition catalysts for $98 \%$ hydrogen peroxide. Air Force Rocket Propulsion Laboratory Report No. AFRPL-TR-67-141, Edwards AFB, California.

22. https://babel.hathitrust.org/cgi/ pt?id=uiug.30112106596627

23. Rice FO, ReiffOM (1927) The thermal decomposition of hydrogen peroxide. Journal of Physical Chemistry 31: 1352-1356.

24. Gordon S, McBride BJ (1994) Computer program for calculation of complex chemical equilibrium compositions and applications. NASA RP-1311.

25. https://apps.dtic.mil/dtic/tr/fulltext/u2/819081.pdf

26. https://www.hitachi-hightech.com/hhs/

27. Defusco A (2018) Historical overview of HTPB the military's preferred solid propellant binder for a half century. Defense Systems Information Analysis Center.

28. Anthoine J, Jean-Yves Lestrade JY, Messineo J, Casu $S$ (2017) Performances of a multi-pulsed hybrid rocket engine operating with highly concentrated hydrogen peroxide. AIAA paper 2017-4006.

29. Rommingen JE, Husdal J (2012) Nammo hybrid rocket propulsion TRL improvement program. AIAA Paper 2012-4311.

30. JF Runckel, CM Willis, LBJ Salters (1963) Investigation of catalyst beds for 98-percent-concentration 
hydrogen peroxide. national aeronautics and space administration, langley station, Hampton, Virginia.

31. Sengupta D, Mazumder S, Cole JV, Lowry S (2004) Controlling non-catalytic decomposition of high concentration hydrogen peroxide. AFRL Contract Report.

32. https://www.semanticscholar.org/paper/ A-Model-for-Thermal-Decompositionof - Hydrogen-Anderson-Corpening / b5db5f62fbb28e91545e1965f849f41f8d69ad20

33. Mok JS, Helms WJ, Sisco JC, William E Anderson (2005) Thermal decomposition of hydrogen peroxide, part I: Experimental results. Journal of Propulsion and Power 21: 942-953.

34. Stephen A Whitmore (2015) Additively manufactured acrylonitrile-butadiene-styrene-nitrous-oxide hybrid rocket motor with electrostatic igniter. J Propulsion and Power 31: 1217-1220.

35. Stephen A Whitmore, Stephen L Merkley, Louis Tonc, Spencer D Mathias (2016) Survey of selected additively manufactured propellants for arc ignition of hybrid rockets. Journal of Propulsion and Power 32: 1494-1504.
36. Whitmore SA, Peterson ZW, Eilers SD (2013) Comparing hydroxyl terminated polybutadiene and acrylonitrile butadiene styrene as hybrid rocket fuels. Journal of Propulsion and Power 29: 582-592.

37. Whitmore SA, Mathias S, Harvey R (2017) High voltage breakdown and arc-tracking mechanism of thermoplastics with applications to hybrid rocket arc- ignition. 53rd AIAA/SAE/ASEE Joint Propulsion Conference, AIAA Propulsion and Energy Forum.

38. Whitmore SA, Merkley DP (2017) Arc-Ignition of a 70\%$85 \%$ hydrogen peroxide/abs hybrid rocket system. $53^{\text {rd }}$ AIAA/SAE/ASEE Joint Propulsion Conference.

39. Whitmore SA, Walker SD, Merkley DP, Sobbi M (2015) High regression rate hybrid rocket fuel grains with helical port structures. Journal of Propulsion and Power 31: 1727-1738.

40. Whitmore SA, Armstrong IW, Heiner MC, Liu L, Martinez CJ (2018) Arc-Ignition of a $90 \% \mathrm{H}_{2} \mathrm{O}_{2}$ hybrid rocket using $A B S$ or HTPB as fuels. AIAA Propulsion and Energy Forum, Cincinnati $\mathrm{OH}$.

41. ht t p s:// w w w. researchgate.net / publication/277799019_Reduced_Toxicity_High_ Performance_Monopropellant 